\title{
Surface Modification of Cured Inorganic Foams with Cationic Cellulose Nanocrystals and Their Use as Reactive Filter Media for Anionic Dye Removal
}

Tuula Selkälä, Terhi Suopajärvi, Juho Antti Sirviö, Tero Luukkonen, Paivo Kinnunen, Ana Luiza Coelho Braga de Carvalho, and Henrikki Liimatainen*

Cite This: ACS Appl. Mater. Interfaces 2020, 12, 27745-27757

Read Online

ABSTRACT: In this work, a surface cationized inorganic-organic hybrid foam was produced from porous geopolymer (GP) and cellulose nanocrystals (CNCs). GPs were synthesized from alkaliactivated metakaolin using $\mathrm{H}_{2} \mathrm{O}_{2}$ as a blowing agent and hexadecyltrimethylammonium bromide (CTAB) as a surfactant. These highly porous GPs were combined at $\mathrm{pH} 7.5$ with cationic CNCs that had been synthesized from dissolving pulp through periodate oxidation followed by cationization in a deep eutectic solvent. The GP-CNC hybrid foams were employed as reactive filters in the removal of the anionic dye, methyl orange (MO; 5-10 $\mathrm{mg} / \mathrm{L}, \mathrm{pH}$ 7). The effects of a mild acid wash and thermal treatments on the structure, properties, and adsorption capacity of the GPs with CNCs and MO were investigated. The CNCs aligned

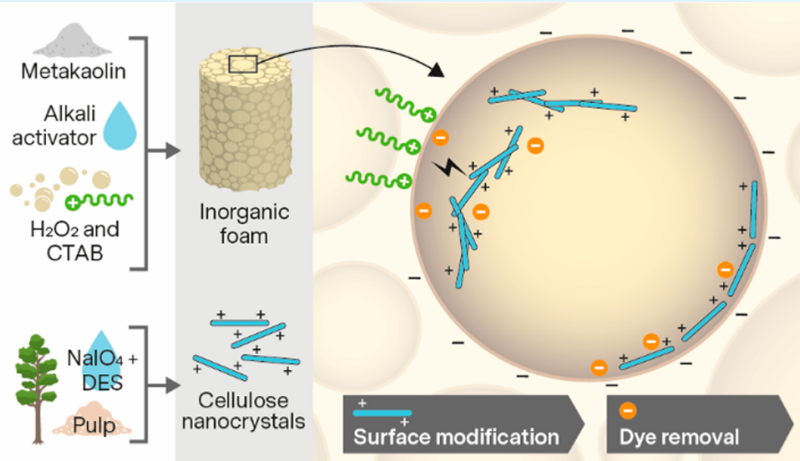
as films and filaments on the surfaces of the neutralized GPs and the addition of CNCs improved MO removal by up to $84 \%$ compared with the reference sample. In addition, CTAB was found to disrupt the attachment of CNCs on the pores and improve adsorption of MO in the GPs with and without CNCs.

KEYWORDS: nanocellulose, DES, micropollutant, wastewater treatment, adsorption, inorganic/organic hybrid

\section{INTRODUCTION}

Inorganic foams composed of ceramic materials, ${ }^{1}$ metals, ${ }^{2,3}$ carbon, ${ }^{4}$ or boron nitride, ${ }^{5}$ also referred to as cellular solids or cellular solid materials, ${ }^{6}$ are by definition ensembles of packed cells in a space with solid edges and faces. ${ }^{7}$ Inorganic foams have been used as lightweight support materials, thermal insulators, in medical applications (scaffolds, implants), electronics, and as absorbents/adsorbents. ${ }^{6,8}$ Highly porous geopolymer foams are a recent addition to the group of inorganic foams.' Pores are commonly introduced into the geopolymers by the incorporation of a blowing agent (e.g., $\mathrm{H}_{2} \mathrm{O}_{2}$ or metallic $\mathrm{Al}$ powder) during synthesis, ${ }^{10,11}$ but other methods exist, such as mechanical foaming, ${ }^{12}$ sacrificial templating, ${ }^{13}$ freeze-casting, ${ }^{14}$ additive manufacturing, ${ }^{15}$ and emulsion templating. ${ }^{16}$

Geopolymers, also known as low-calcium alkali-activated materials, are amorphous to semicrystalline materials synthesized by reacting aluminosilicate precursors (e.g., metakaolin, fly ash) with concentrated aqueous alkaline solutions (e.g., sodium hydroxide and/or sodium silicate). ${ }^{17,18}$ As a result, a negatively charged three-dimensional and interconnected aluminosilicate $(\mathrm{Si}-\mathrm{O}-\mathrm{Al})$ framework is formed. The negative charge (originating from four-coordinated $\mathrm{Al}$ ) is balanced by cations (e.g., $\mathrm{Na}^{+}$or $\mathrm{K}^{+}$) that are present in the framework cavities. Geopolymers have been extensively studied as replacements for Portland cement, ${ }^{19}$ but, due to the high intrinsic cation exchange capacity, they have also been used (typically in powdered form) as adsorbents for the removal of cationic dyes (e.g., methylene blue) and heavy metals (e.g., $\left.\mathrm{Cu}^{2+}, \mathrm{Ni}^{2+}, \mathrm{Pb}^{2+}\right) \cdot{ }^{20,21}$ The introduction of large open pores ( $\mu \mathrm{m}$ scale) to the geopolymer structure widens their prospects in adsorption applications ${ }^{9}$ because of the increased water permeability and available surface area. Consequently, these porous spheres $^{22,23}$ and monoliths ${ }^{24,25}$ can be used instead of powders as adsorption media, which simplifies the separation of adsorbent and regeneration.

The pollution of the aquatic environment with emerging contaminants (ECs), such as pharmaceuticals, hormones, and dyes, is suspected to have adverse impacts on humans and

Received: March 31, 2020

Accepted: May 26, 2020

Published: May 26, 2020 
ecosystems. $^{26,27}$ Particular attention should be paid to small, polar, anionic, and nonvolatile molecules as these properties increase their mobility in the environment and hinder removal during conventional wastewater treatment processes. ${ }^{28}$ Adsorption is considered to be a prominent pretreatment method $^{29}$ in the EC removal because of its simplicity, efficiency, and the possibility of using abundant and low-cost materials, such as agricultural ${ }^{30}$ or mineral waste (e.g., fly ash $)^{21}$ as raw materials. However, negatively charged ECs, such as anionic dyes, are often challenging to remove with inorganic adsorbent materials due to the intrinsic anionic surface charge of the framework. Geopolymers, for example, typically have negative $\zeta$-potential at $\mathrm{pH} 2-12$. $^{2,24}$ However, a fly ash-based geopolymer has been reported to be capable of adsorbing anionic surfactant sodium dodecyl benzenesulfonate (SDBS). ${ }^{31}$ According to the $\zeta$-potential measurement, the geopolymer particles were positively charged at $\mathrm{pH}<7.04$ and negatively charged at $\mathrm{pH}>7.04$, which explained the highest removal efficiency obtained at $\mathrm{pH} 2$ and the sharp decrease in the surfactant removal at higher $\mathrm{pH}$ values. However, such acidic conditions are not feasible in larger-scale applications. Thus, effective removal of persistent anionic pollutants at nearneutral $\mathrm{pH}$ requires the surface chemistry of a geopolymer foam to be altered.

Cellulose nanoparticles, i.e., cellulose nanofibers (CNFs) and cellulose nanocrystals ( $\mathrm{CNCs}$ ), are biobased materials that are recognized for their potential to act as adsorbents in water treatment applications due to their hydrophilicity, high surface area-to-volume ratio, low toxicity, and the possibility to add a wide variety of functional groups to the cellulose backbone. ${ }^{32}$ One novel and sustainable approach to cellulose modification is the use of deep eutectic solvents (DESs). DESs can be produced from safe bulk chemicals, and they have been shown to act not only as a reaction medium but also as a reagent in the production of functionalized CNFs and CNCs. ${ }^{33-37}$ The most prominent challenge related to the use of nanosized cellulose particles alone as adsorbents is the difficulty in separating the exhausted particles from the solution. ${ }^{38}$ Therefore, cellulose nanoparticles are often used in combination with other materials, such as (nano)clay minerals, ${ }^{39}$ metal particles, ${ }^{40}$ and metal-organic frameworks (MOFs). ${ }^{41}$ These hybrid materials can be removed after treatment, e.g. by an external magnetic field ${ }^{40}$ or through charge neutralization with other nanoconstituents, such as halloysite nanotubes or kaolin. $^{39}$

Porous geopolymer foams are a promising substrate for cellulose nanoparticles due to their large surface areas and rigid nature. Cellulose ${ }^{42,43}$ and natural cellulosic fibers (e.g., flax, bamboo, cotton $)^{44-46}$ have been used as a reinforcement agent in the geopolymer matrix due to their low densities, affordability, and good mechanical properties. However, the combination of cellulose nanoparticles with geopolymers has scarcely been studied, ${ }^{47}$ and indeed no information is available on the surface modification of geopolymers with cellulose nanoparticles. One of the biggest obstacles hindering geopolymer surface modification with cellulose nanoparticles is the presence of free alkali in the material after geopolymerization, ${ }^{48,49}$ which can trigger the degradation of the biopolymer if there is prolonged contact. ${ }^{47}$ Therefore, extra effort must be made to effectively reduce the alkalinity of the geopolymer. In the case of geopolymer blocks, this has been achieved through excessive washing with water ${ }^{11,22}$ or acids. ${ }^{42,43}$
In this work, we report the surface modification of a porous metakaolin geopolymer foam with cationic CNCs produced from wood cellulose through periodate oxidation and a DESmediated imination reaction. The geopolymer-CNC hybrid foams were then demonstrated as reactive filter media for the removal of the aqueous anionic dye, methyl orange (MO), at $\mathrm{pH}$ 7. In addition, the effects of acid and thermal treatments on the structure, properties, and adsorption capacity of geopolymer foams with CNCs and MO were investigated. The chemical and structural characteristics of CNCs were analyzed using energy-filtered transmission electron microscopy (EFTEM), diffuse reflectance infrared Fourier transform spectroscopy (DRIFT), polyelectrolyte titration, and $\zeta$ potential measurement. The geopolymer foams were analyzed using X-ray diffraction (XRD), X-ray fluorescence (XRF), field emission scanning electron microscopy (FESEM), BrunauerEmmett-Teller and Barrett-Joyner-Halenda methods (BET$\mathrm{BJH})$, thermogravimetric analysis (TGA), and $\zeta$-potential measurement. The MO removal was quantified using ultraviolet-visible spectroscopy (UV-vis).

\section{MATERIALS AND METHODS}

2.1. Raw Materials and Chemicals. All reagents were used asreceived, and deionized water was used throughout the experiments. Metakaolin (MetaMax, 53.0 weight-\% $\mathrm{SiO}_{2}, 44.5$ weight- $\% \mathrm{Al}_{2} \mathrm{O}_{3}$; BASF, Germany), sodium silicate solution (extra pure, $7.5-8.5 \%$ $\mathrm{Na}_{2} \mathrm{O}, 25.5-28.5 \% \mathrm{SiO}_{2}$, molar $\mathrm{SiO}_{2} / \mathrm{Na}_{2} \mathrm{O}=3.5$, water content $\approx 64$ weight-\%; Merck, Germany), $\mathrm{NaOH}$ (98.7\%; VWR, Czech Republic), $\mathrm{H}_{2} \mathrm{O}_{2}$ (30\%; VWR, France), and CTAB (hexadecyltrimethylammonium bromide, $\geq 98 \%$; Sigma-Aldrich, India) were used in the production of the geopolymer foams. Acetic acid (100\%; Merck, Germany) was diluted to $0.1 \mathrm{M}$ before use in the acid wash of the geopolymer foams.

Wet disintegrated sheets of commercial softwood dissolving pulp (cellulose 96.2\%, hemicelluloses 3.5\%, total lignin $<0.5 \%$, acetone soluble extractives $0.17 \%$; Domsjö Fabriker AB, Sweden) was used as the cellulose raw material. $\mathrm{LiCl}$ ( $\geq 99 \%$; Sigma-Aldrich, Germany), sodium metaperiodate ( $\geq 99.0 \%$; Sigma-Aldrich, India), glycerol (99.5\%; VWR, Belgium), aminoguanidine hydrochloride (>98.0\%; TCI, Japan), and ethanol (96\%; VWR, France) were used in the chemical modification of the cellulose fibers.

Methyl orange (85\%; Sigma-Aldrich, U.S.A.) was used in the dye removal experiments. For $\mathrm{pH}$ adjustment, $0.1 \mathrm{M} / 1 \mathrm{M} \mathrm{NaOH}$ and 0.1 $\mathrm{M} \mathrm{HCl}$ (Oy FF-Chemicals Ab, Finland) were used. Commercial 0.5 $\mathrm{M}$ buffer solutions were used in the charge density measurements of the cationic CNCs (citric acid/sodium citrate dihydrate $\mathrm{pH} 3$, citric acid/sodium citrate dihydrate $\mathrm{pH} 5$, sodium phosphate monobasic/ sodium phosphate dibasic $\mathrm{pH} 7$, sodium phosphate monobasic/ sodium phosphate dibasic $\mathrm{pH} 8$, sodium bicarbonate/sodium carbonate $\mathrm{pH} 9$, and sodium bicarbonate/sodium carbonate $\mathrm{pH} 10$; Alfa Aesar, Germany). Anionic sodium polyethylene sulfonate (Pes$\mathrm{Na}, 0.001 \mathrm{~N}$; BTG Instruments $\mathrm{GmbH}$, Germany) was employed as the titrant. $\mathrm{TiO}_{2}$ (rutile, $\geq 99.9 \%$; Aldrich, Japan) was used as an internal standard in XRD measurements of geopolymer samples, and uranyl acetate (98\%; Polysciences Inc., U.S.A.) was used for negative staining of the CNCs prior to EFTEM imaging.

2.2. Synthesis of Geopolymer Foams. Alkali activator solution was prepared by mixing the sodium silicate solution $(100 \mathrm{~g})$ with $\mathrm{NaOH}$ pellets $(11.8 \mathrm{~g})$ overnight in a closed plastic bottle. CTAB (Figure 1A) ( $0.1 \mathrm{~g}$ dissolved in $1 \mathrm{~mL}$ of water) was added to the activator solution and mixed effectively for $10 \mathrm{~min}$. Metakaolin (63.1 g) was gradually added into the activator solution over 3 min using an overhead mixer (IKA Eurostar 60 digital, Germany) at $1200 \mathrm{rpm}$, after which the mixing was continued for $7 \mathrm{~min}$. Then, $\mathrm{H}_{2} \mathrm{O}_{2}$ solution $(5.4 \mathrm{~mL})$ was added to the mixture, and the mixing was continued for another $1 \mathrm{~min}$ at $1200 \mathrm{rpm}$. The homogenized mixture was poured into cylindrical poly(methyl methacrylate) (PMMA) plastic molds 


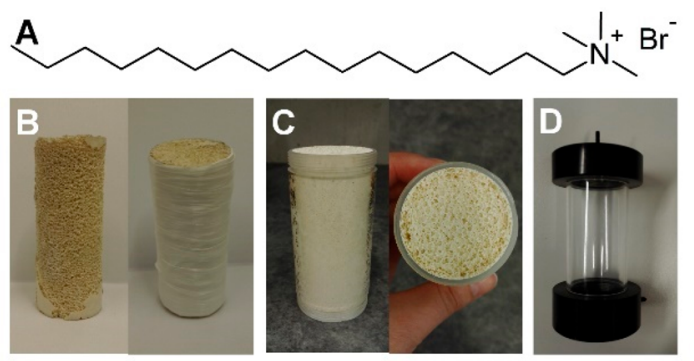

Figure 1. (A) Chemical structure of surfactant CTAB; (B) heattreated geopolymer foam sample (GP-H) after demolding and before insertion into the column; (C) geopolymer foam (GP) molded directly into the column; and (D) column combined with top and bottom parts containing the liquid inlet and outlet.

(inner height of $101 \mathrm{~mm}$, diameter of $44 \mathrm{~mm}$, and volume of $0.15 \mathrm{~L}$ ), which were placed inside a plastic bag. The samples were cured at 60 ${ }^{\circ} \mathrm{C}$ for $4 \mathrm{~h}$. The geopolymer had the following molar ratios: $\mathrm{SiO}_{2} /$ $\mathrm{Al}_{2} \mathrm{O}_{3}=3.65, \mathrm{Na}_{2} \mathrm{O} / \mathrm{SiO}_{2}=0.27, \mathrm{Na}_{2} \mathrm{O} / \mathrm{Al}_{2} \mathrm{O}_{3}=1.00$, and $\mathrm{H}_{2} \mathrm{O} /$ $\mathrm{Na}_{2} \mathrm{O}=14.1$. The fresh paste had a water content of $40 \%(\mathrm{w} / \mathrm{w})$.

Half of the cured geopolymer foams (referred to as GP) were demolded, and the top and bottom parts of the samples were gently smoothened with abrasive paper to reveal the pores. The samples were rinsed with water, placed in Teflon cups and treated hydrothermally at $121{ }^{\circ} \mathrm{C}$ and 1 bar for $1 \mathrm{~h}$ using an autoclave (Steralis Stèrimax S18-W1, France). The samples (referred to as GP$\mathrm{HT}$ ) were rinsed with water, and the excess water was removed with pressurized air. Organic matter was burned away from the samples in a muffle furnace (Nabertherm L5/11/P320, Germany) (heated to $105{ }^{\circ} \mathrm{C}$ in $30 \mathrm{~min}$ and kept at $105^{\circ} \mathrm{C}$ for $4 \mathrm{~h}$, then heated to $525^{\circ} \mathrm{C}$ in $2.5 \mathrm{~h}$ and kept at $525{ }^{\circ} \mathrm{C}$ for $3 \mathrm{~h}$ ). After the heat treatments, the samples (referred to as GP-H) were fixed into PMMA plastic columns that had the same dimensions as the molds. As the hydrothermal and furnace treatments caused the GP-H samples to shrink slightly, poly(tetrafluoroethylene) (PTFE) tape (Unipak Unitape, Denmark), Parafilm M (Bemis Company Inc., U.S.A.) and silicone paste (Henkel Pattex Healthy Kitchen \& Bathroom Sanitary Silicone, Sweden) were used to seal the samples tightly against the column walls (Figure 1B), after which the samples were dried at room temperature overnight. The other half of the cured geopolymer samples (GPs) were kept in the molds, and only the top and bottom parts were smoothened with abrasive paper (Figure 1C).

2.3. Cationization of Cellulose and Disintegration into Nanocrystals. Cationized dialdehyde cellulose (CDAC) was synthesized according to a previously reported ${ }^{34}$ two-step procedure (Scheme 1). In the first step, cellulose was converted to dialdehyde cellulose (DAC) by selectively oxidizing the vicinal hydroxyl groups to aldehyde groups using sodium metaperiodate. $\mathrm{LiCl}$ disrupted the hydrogen bond network of cellulose and improved the oxidation efficiency by exposing more hydroxyl groups to periodate. In the second step, DAC was cationized in an aminoguanidine hydro- chloride-glycerol (AhG) DES, which acted as both a reaction medium and a reagent (aminoguanidine hydrochloride).

In the synthesis of DAC, $1 \%(\mathrm{w} / \mathrm{w})$ dissolving pulp ( $10 \mathrm{~g}$ abs.) in deionized water was reacted with sodium metaperiodate $(8.2 \mathrm{~g})$ in the presence of $\mathrm{LiCl}(18 \mathrm{~g})$ for $3 \mathrm{~h}$ at $75{ }^{\circ} \mathrm{C}$. Ethanol $(500 \mathrm{~mL})$ was added to stop the reaction, after which the mixture was filtered to collect DAC. The DAC fibers were rinsed with 50:50 ethanol:water solution $(500 \mathrm{~mL})$, then mixed with ethanol $(500 \mathrm{~mL})$ for $15 \mathrm{~min}$, filtered, and finally washed with ethanol $(250 \mathrm{~mL})$. The yield of the first reaction was $80 \%$. In the synthesis of CDAC, AhG DES was first prepared by heating and mixing aminoguanidine hydrochloride ( 52.5 g) and glycerol $(87.5 \mathrm{~g})$ in a beaker at $90{ }^{\circ} \mathrm{C}$ in an oil bath until a clear liquid was formed. The temperature was adjusted to $80^{\circ} \mathrm{C}$, after which DAC ( $7 \mathrm{~g}$ abs.) was added. The DES-DAC mixture was effectively mixed for $10 \mathrm{~min}$, after which ethanol $(250 \mathrm{~mL})$ was added, under stirring, to the mixture. After filtration, the collected CDAC was thoroughly washed with ethanol $(2 \times 500 \mathrm{~mL})$. Finally, CDAC was mixed with deionized water $(500 \mathrm{~mL})$ for $1 \mathrm{~h}$ and collected by filtration. The yield of the second reaction was $110 \%$.

Cationic CNCs were produced from $1 \%(\mathrm{w} / \mathrm{w})$ aqueous CDAC dispersion by mechanical disintegration using a microfluidizer (Microfluidics M-110EH-30, U.S.A.). The CDAC dispersion was passed twice through 400 and $200 \mu \mathrm{m}$ chambers at a pressure of 1000 bar. The dry matter content of the resulting CNC suspension was determined from oven-dried $\left(105^{\circ} \mathrm{C}\right)$ samples.

2.4. Production of CNC-Geopolymer Foam Hybrids. Geopolymer samples GP and GP-H (directly molded or fixed afterward in columns, Figure $1 \mathrm{~B}$ and $1 \mathrm{C}$ ) were washed with $0.1 \mathrm{M}$ acetic acid to remove the excess alkali before combining with CNCs. Acetic acid solution ( $1 \mathrm{~L})$ was circulated through the column (bottom-up direction, Figure 1D) overnight at $15.5 \mathrm{rpm}(8.5 \mathrm{~mL} / \mathrm{min})$ using a peristaltic pump (Abimed Gilson Minipuls 3, Germany) with silicone tubing (inner diameter $2 \mathrm{~mm}$ ). Then, the geopolymer samples (referred to as GP-AA and GP-H-AA) were rinsed until neutrality by pumping deionized water through the column at $48 \mathrm{rpm}(0.96 \mathrm{~L} / \mathrm{h})$. The $1 \%(\mathrm{w} / \mathrm{w})$ CNC suspension was diluted with deionized water to $0.1 \%(\mathrm{w} / \mathrm{w})(600 \mathrm{~mL})$, and the $\mathrm{pH}$ was adjusted to 7.50 with $1 \mathrm{M}$ $\mathrm{NaOH}$. A sample (1 mL, equal to $1 \mathrm{mg}$ of CNCs) was taken from the $\mathrm{CNC}$ suspension for initial charge density determination. Then, the remaining $\mathrm{CNC}$ suspension was circulated through the geopolymer GP-AA and GP-H-AA columns in bottom-up direction using a peristaltic pump at $10 \mathrm{rpm}(5 \mathrm{~mL} / \mathrm{min})$ for 6 days (Figure S1Aof the Supporting Information, SI). A sample $(1 \mathrm{~mL})$ was taken from the CNC suspension at regular intervals (1-3 days) for charge density measurement, and the $\mathrm{pH}$ of the suspension was recorded. The formed hybrids were referred to as GP-AA-CNC and GP-H-AA-CNC.

2.5. Dye Removal Experiments. Acid-washed geopolymers and heat-treated acid-washed geopolymers with and without CNCs (GPAA, GP-AA-CNC, GP-H-AA, and GP-H-AA-CNC) were applied as filtration columns for MO removal. The columns were not dried between the acid wash/CNC addition and dye removal experiments because drying agglomerates CNCs. The quantification of $\mathrm{MO}$ in the experiments was done using UV-vis spectroscopy (Shimadzu UV1800, Japan) at $464 \mathrm{~nm}$ using quartz cuvettes. The spectrum was recorded at $200-800 \mathrm{~nm}$ for each sample to detect any changes in the

Scheme 1. Cationization of Oxidized Cellulose Pulp in Aminoguanidine Hydrochloride-Glycerol Deep Eutectic Solvent

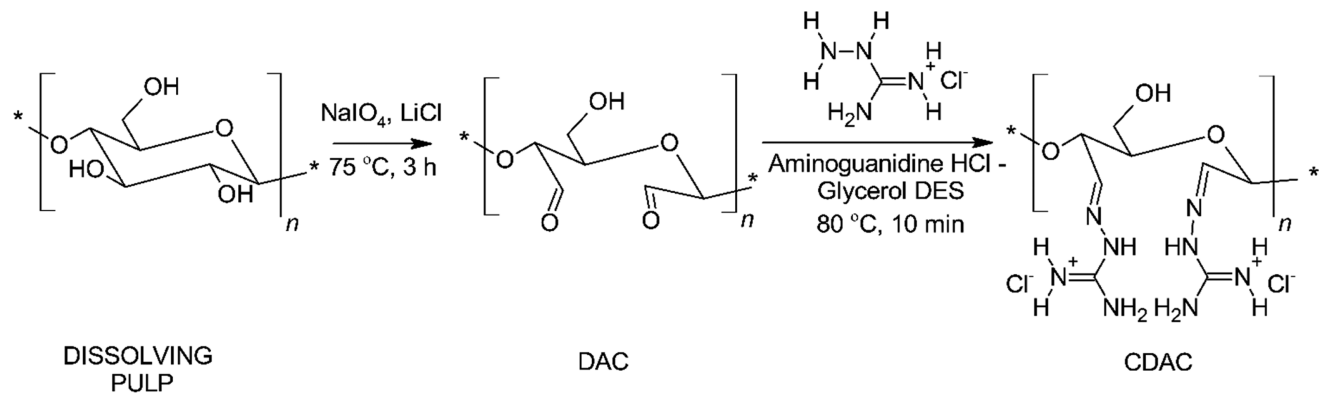


location of the absorbance maximum. Calibration was performed for the $\mathrm{MO}$ concentration range of $0-20 \mathrm{mg} / \mathrm{L}$ at $\mathrm{pH} 7$ (Figure S2). Deionized water was used for baseline corrections. An MO solution ( 5 or $10 \mathrm{mg} / \mathrm{L}$ ) was prepared by diluting the MO stock solution $(1000 \mathrm{mg} / \mathrm{L})$ with deionized water using a volumetric flask $(100 \mathrm{~mL})$. The $\mathrm{pH}$ of the resulting $\mathrm{MO}$ solution was adjusted to 7.00 by adding a few microliters of $0.1 \mathrm{M} \mathrm{HCl} / \mathrm{NaOH}$. Using a peristaltic pump at 12 $\mathrm{rpm}(5 \mathrm{~mL} / \mathrm{min})$, the solution was dripped onto the surface of each column, and the filtrate was collected (Figure S1B). The $\mathrm{pH}$, the weight, and the absorbance of the filtrate were recorded. Then, the filtrate solution was passed through the columns again, and the $\mathrm{pH}$, weight, and absorbance were recorded. The procedure was repeated five times in total. The percentage of removed MO from solution was calculated using eq 1 :

$$
\text { MO removed }(\%)=\left[\left(C_{0}-C_{t}\right) / C_{0}\right] \times 100
$$

where $C_{0}(\mathrm{mg} / \mathrm{L})$ is the initial MO concentration, and $C_{t}(\mathrm{mg} / \mathrm{L})$ is the $\mathrm{MO}$ concentration after each filtration cycle.

2.6. Material Characterization. For XRF, XRD, TGA, and $\zeta$ potential analyses, powdered geopolymer samples were used. The synthesized geopolymer foams were first crushed by hand and, when needed, mixed overnight with $0.1 \mathrm{M}$ acetic acid. The acid was removed by centrifugation at $7517 \mathrm{rpm}$ for $5 \mathrm{~min}$ at $20^{\circ} \mathrm{C}$ (Beckman Coulter Avanti J-26 XPI, U.S.A.) and consequently washed with water $(500 \mathrm{~mL})$ three times. After each wash, the water was removed by centrifugation. The resulting samples were dried in an oven at $105^{\circ} \mathrm{C}$ overnight and stored in a desiccator prior to analysis.

2.6.1. Characterization of Chemical Composition of Geopolymers by XRF. The chemical composition of the geopolymer samples was determined using a $4 \mathrm{kV}$ wavelength dispersive XRF spectrometer (Malvern Panalytical Axios mAX, The Netherlands). The samples $(8.25 \mathrm{~g})$ were ground to a fine powder and compressed into tablets before the analysis. The XRF data was interpreted using Omnian software (Malvern Panalytical, The Netherlands).

2.6.2. Characterization of Thermal Decomposition of Geopolymers by TGA. The TGA measurements were performed with a PrepASH 340 ash analyzer (Precisa, Switzerland) under air. Samples $(0.5-1.7 \mathrm{~g})$ were heated in a crucible from 25 to $105^{\circ} \mathrm{C}$ in $30 \mathrm{~min}$, kept at $105{ }^{\circ} \mathrm{C}$ for $4 \mathrm{~h}$, heated to $525^{\circ} \mathrm{C}$ in $2.5 \mathrm{~h}$, kept at $525^{\circ} \mathrm{C}$ for 3 $\mathrm{h}$, and finally heated to $950{ }^{\circ} \mathrm{C}$ in $1 \mathrm{~h}$ and kept at $950{ }^{\circ} \mathrm{C}$ for $3 \mathrm{~h}$. The loss on ignition at 525 and $950{ }^{\circ} \mathrm{C}\left(\mathrm{LOI}_{525}\right.$ and $\mathrm{LOI}_{950}$, respectively) was determined by comparing the dry weight at 525 and $950{ }^{\circ} \mathrm{C}$ with the dry weight at $105^{\circ} \mathrm{C}$, respectively.

2.6.3. Characterization of Geopolymer Structure by XRD. XRD analysis was performed using a Rigaku SmartLab $9 \mathrm{~kW}$ diffractometer (Japan) with $\mathrm{CuK}_{\beta}$ radiation over a $2 \theta$ range of $5-130^{\circ}$ at a scanning speed of $4^{\circ} \mathrm{min}^{-1}$ and a step of $0.02^{\circ}$. Before analysis, samples GP-AA and GP-H-AA underwent additional grinding for $3 \mathrm{~min}$ at a speed of $1400 \mathrm{~min}^{-1}$ using a vibratory disc mill (Retsch RS 100, Germany), after which they were sieved to $<62 \mu \mathrm{m}$. Other samples were ground by hand using a mortar and sieved to $<105 \mu \mathrm{m}$. Rutile $(10 \% \mathrm{w} / \mathrm{w})$ was added to the samples as an internal standard for the quantification of crystalline phases.

2.6.4. Characterization of Surface Charge of Geopolymers and CNCs by $\zeta$-Potential. Before analysis, the geopolymer samples were ground for $3 \mathrm{~min}$ at a speed of $1400 \mathrm{~min}^{-1}$ using a vibratory disc mill (Retsch RS 100, Germany) and sieved to $<62 \mu \mathrm{m}$. The true densities of the powders were determined using a gas pycnometer (Micrometrics AccuPyc II 1340, U.S.A.), using helium gas as the displacement medium. The particle sizes of the powders were measured by laser diffraction (Beckman Coulter LS 13 320, U.S.A.) from a $0.2 \%(\mathrm{w} / \mathrm{v})$ water slurry that had been ultrasonicated $(37 \mathrm{kHz}$, pulse mode, $100 \%$ power) with overhead mixing for $15 \mathrm{~min}$ before measurement. The geopolymer sample $(\sim 0.8 \mathrm{~g})$ was poured into the graduated cylinder containing deionized water $(500 \mathrm{~mL})$, after which the suspension was homogenized by agitating the capped cylinder 10 times. The suspension was allowed to settle until a solid concentration of $0.1 \%(\mathrm{w} / \mathrm{w})$ composed of particles below $10 \mu \mathrm{m}$ was reached (calculated using Stokes Law). Then, a sample $(100 \mathrm{~mL})$ of the supernatant was taken, and the $\zeta$-potential was measured (Malvern
Pananalytical Zetasizer Nano Z, U.K.) in the $\mathrm{pH}$ range 2-11.5 (adjusted with $\mathrm{NaOH} / \mathrm{HCl})$. The $1 \%(\mathrm{w} / \mathrm{w}) \mathrm{CNC}$ suspension was diluted with deionized water to $0.1 \%(\mathrm{w} / \mathrm{w})$ before $\zeta$-potential measurement.

2.6.5. Characterization of Geopolymer Nanometer-Scale Porosity and Specific Surface Area. Specific surface areas and pore volumes of the geopolymer samples were determined from $\mathrm{N}_{2}$ gas adsorption-desorption isotherms using a Micromeritics ASAP 2020 instrument (U.S.A.). The samples were pretreated at $70{ }^{\circ} \mathrm{C}$ for $24 \mathrm{~h}$ before analysis. The specific surface area was calculated based on the Brunauer-Emmett-Teller (BET) isotherm, and pore-size distributions were calculated from the desorption data using Barrett-JoynerHalenda (BJH) method. ${ }^{50}$ Total porosity was calculated using eq 2 :

$$
\text { total porosity }(\%)=\left[\left(\rho_{\mathrm{t}}-\rho_{\mathrm{g}}\right) / \rho_{\mathrm{t}}\right] \times 100
$$

where $\rho_{\mathrm{t}}$ is the true density $\left(\mathrm{g} / \mathrm{cm}^{3}\right)$ obtained from pulverized $(<105$ $\mu \mathrm{m}$ ) samples using the helium pycnometer (Micrometrics AccuPyc II 1340 , U.S.A.), and $\rho_{\mathrm{g}}$ is the geometric density $\left(\mathrm{g} / \mathrm{cm}^{3}\right)$ determined from dry samples (foam blocks) using an analytical balance and a caliper.

2.6.6. Characterization of Charge Density of CNCs by Polyelectrolyte Titration. The $1 \%(\mathrm{w} / \mathrm{w})$ CNC suspension was diluted with deionized water to $0.1 \%(\mathrm{w} / \mathrm{w})$. Buffer stock solutions $(0.5 \mathrm{M})$ in the $\mathrm{pH}$ range of $3-10$ were diluted to $0.5 \mathrm{mM}$ with deionized water, and the $\mathrm{pH}$ was adjusted with $0.1 \mathrm{M} \mathrm{NaOH} / \mathrm{HCl}$. The samples for measurement were prepared by mixing $1 \mathrm{~mL}$ CNC suspension and $9 \mathrm{~mL}$ buffer solution in the sample cell of the particle charge detector (Mütek PCD 03, U.S.A.), after which the mixture was titrated with Pes-Na. CNC samples $(1 \mathrm{~mL})$ from the geopolymerCNC combination experiments were mixed with $9 \mathrm{~mL}$ of deionized water, and the mixture was titrated with Pes-Na. The amount of CNC in the solution at each data point was calculated by comparing the Pes-Na consumption with the consumption at $t=0$ (charge density of $1 \mathrm{mg}$ of $\mathrm{CNCs}$ ).

2.6.7. Characterization of Cellulose Structure by DRIFT Spectroscopy. DRIFT spectra were collected with a Bruker Vertex $80 \mathrm{v}$ spectrometer (U.S.A.) for the oven- or freeze-dried cellulose samples (pulp, DAC, CDAC). The spectra were recorded in the wavenumber $600-4000 \mathrm{~cm}^{-1}$ using 40 scans with a resolution of $2 \mathrm{~cm}^{-1}$.

2.6.8. Characterization of the Morphology of CNCS by EFTEM. EFTEM samples were prepared by dropping the diluted nanocellulose suspension $(0.01 \% \mathrm{v} / \mathrm{v})$ on a carbon-coated copper grid. Uranyl acetate $(2 \% \mathrm{w} / \mathrm{v})$ was used in the negative staining of the samples, after which the samples were dried at room temperature. Images were captured with a TVIPS TemCam-F416 camera (Germany), using $100 \mathrm{kV}$ as an accelerating voltage (JEOL JEM-2200FS, Japan). The widths and lengths of individual nanocrystals $(n=120)$ were measured from images with ImageJ/FIJI processing software (National Institutes of Health, U.S.A.). The height and width distribution peaks were evaluated through Gaussian fitting (OriginPro 2018 software; Origin-Lab Corporation, U.S.A.).

2.6.9. Characterization of Geopolymer and CNC-Geopolymer Hybrid Morphologies by FESEM. FESEM samples were prepared by cutting pieces from the top and middle parts of the CNC-geopolymer hybrids (used in MO removal, wet), after which they were frozen in liquid $\mathrm{N}_{2}$ and dried in a freeze-dryer (LaboGene Scanvac CoolSafe, Denmark) overnight. Geopolymer samples that did not contain $\mathrm{CNCs}$ were dried at $105{ }^{\circ} \mathrm{C}$ prior to freezing and freeze-drying. Images were captured from carbon-coated samples using $5 \mathrm{kV}$ accelerating voltage (Zeiss Ultra Plus, Germany).

\section{RESULTS AND DISCUSSION}

3.1. Characteristics of Geopolymer Foams and the Impact of Thermal Treatments and Acid Wash. The alkali-activation process used in the production of the geopolymer foams included the following main steps: (1) dissolution of aluminosilicate source (in our case metakaolin), (2) speciation and equilibrium of aluminate and silicate, (3) gelation, (4) reorganization, and (5) polymerization and 
hardening. ${ }^{51}$ The added $\mathrm{H}_{2} \mathrm{O}_{2}$ decomposed into oxygen gas $\left(\mathrm{O}_{2}\right)$ and water in the alkaline geopolymer paste. ${ }^{32}$ The interface between $\mathrm{O}_{2}$ gas bubbles and aqueous phase in the fresh geopolymer paste was stabilized (e.g., their coalescence was prevented) with surfactant CTAB. The entrapment of these bubbles in the geopolymer paste resulted in the formation of a highly porous foamy structure during curing. The raw material selected for the geopolymer foam production was metakaolin because of its purity and consistent chemical composition compared with industrial byproducts (e.g., fly ash). ${ }^{53}$ CTAB was used as a surfactant because, based on the preliminary tests, it was found to produce a highly porous and water permeable structure with homogeneous pore-size distribution when combined with $\mathrm{H}_{2} \mathrm{O}_{2}$.

The cured geopolymer foams required further processing before they were brought together with CNCs because cellulose and cellulose nanoparticles are prone to degradation in alkaline conditions ${ }^{47}$ and geopolymers are known to be highly alkaline due to residual $\mathrm{NaOH}$ remaining in the pore water after synthesis. ${ }^{48,49}$ Consequently, there are four main sample types discussed in this section: Cured geopolymer foams (GP), acid-washed cured geopolymer foams (GP-AA), heat-treated cured geopolymer foams (GP-H), and heattreated and acid-washed cured geopolymer foams (GP-H-AA). In some procedures, metakaolin geopolymers are ground to a fine powder and washed numerous times with water before use in adsorption experiments. ${ }^{54,55}$ This method was, however, not applicable in our case because of the highly porous, continuous monolith structure of the fabricated foams. Thus, the foams were washed overnight with dilute acid to guarantee their efficient neutralization. On the basis of the preliminary experiments, $0.1 \mathrm{M}$ acetic acid was chosen (samples referred to as GP-AA and GP-H-AA) as it was less corrosive to the geopolymer than $0.1 \mathrm{M} \mathrm{HCl}$.

Heat treatment was selected as an adjacent strategy for alkalinity reduction. First, GP samples were treated hydrothermally using an autoclave (samples referred to as GP-HT) to ensure that the components had fully reacted and that the amount of unreacted $\mathrm{NaOH}$ was as low as possible. Hydrothermal treatment of cured metakaolin geopolymers can also result in the formation of zeolites when continued for $10-18 \mathrm{~h}$ at $90-140{ }^{\circ} \mathrm{C} .^{56-59}$ In this case, however, zeolite formation was not expected due to the short duration of the hydrothermal treatment $(1 \mathrm{~h})$. The GP-HT samples were then heated to a maximum temperature of $525{ }^{\circ} \mathrm{C}$ (annealing, samples referred to as GP-H). This was to reduce the amount of CTAB surfactant (i.e., organic carbon) from the GP samples because it was suspected that $\mathrm{CTAB}$ can introduce a cationic charge ${ }^{60}$ to the GP structure and interfere with the adsorption of cationic CNCs through electrostatic repulsion. After the heat treatment, the GP-H samples were washed with acetic acid to remove any residual $\mathrm{NaOH}$ (samples referred to as GPH-AA).

According to the XRD results (Figure 2), all geopolymer samples had a broad peak centered at around $30^{\circ} 2 \theta$, which confirmed that the samples remained amorphous ${ }^{61}$ despite the heat and/or acid treatments, as expected. The peaks originated from rutile that was used as an internal standard (containing anatase impurities). The morphologies of the different geopolymer samples did not differ significantly from each other either (Figure S3). Interconnected pore structures were observed in all samples and the largest pores were approximately $1 \mathrm{~mm}$ in diameter. The GP-HT sample was

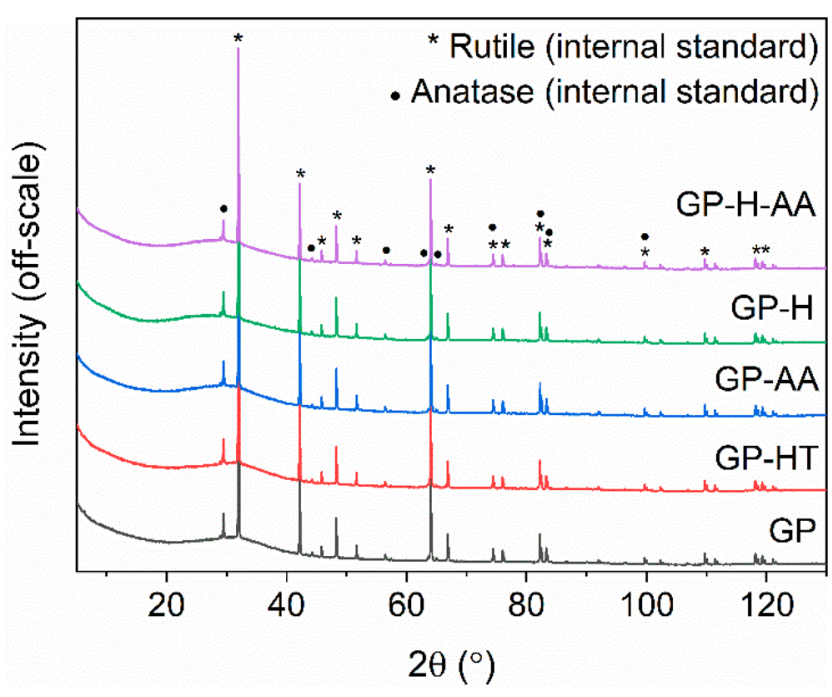

Figure 2. Diffractograms of geopolymer (GP), hydrothermally treated geopolymer (GP-HT), acid-washed geopolymer (GP-AA), heattreated geopolymer (GP-H), and heat-treated acid-washed geopolymer (GP-H-AA). Samples contained $10 \%(\mathrm{w} / \mathrm{w})$ of rutile as an internal standard (containing anatase impurity).

not studied further because it was unlikely that it would greatly differ from the GP sample.

XRF results (Table 1) showed that the acid wash reduced the alkaline metal content of the samples because the amount

Table 1. Chemical Composition and Loss on Ignition of the Studied Samples

\begin{tabular}{|c|c|c|c|c|}
\hline composition (wt \%) & GP & GP-AA & GP-H & GP-H-AA \\
\hline $\mathrm{SiO}_{2}$ & 48.1 & 52.0 & 48.8 & 51.4 \\
\hline $\mathrm{Al}_{2} \mathrm{O}_{3}$ & 22.4 & 24.7 & 23.1 & 24.3 \\
\hline $\mathrm{Na}_{2} \mathrm{O}$ & 15.2 & 8.9 & 15.0 & 9.7 \\
\hline $\mathrm{TiO}_{2}$ & 0.9 & 1.0 & 0.9 & 1.0 \\
\hline $\mathrm{FeO}$ & 0.2 & 0.2 & 0.2 & 0.2 \\
\hline $\mathrm{K}_{2} \mathrm{O}$ & 0.06 & 0.06 & 0.07 & 0.07 \\
\hline $\mathrm{P}_{2} \mathrm{O}_{5}$ & 0.04 & 0.04 & 0.02 & 0.03 \\
\hline $\mathrm{CaO}$ & 0.01 & 0.02 & 0.01 & 0.01 \\
\hline $\mathrm{MgO}$ & & & & 0.01 \\
\hline $\mathrm{Cl}$ & 0.03 & 0.01 & 0.02 & 0.02 \\
\hline $\mathrm{Br}$ & 0.013 & $<0.003^{a}$ & 0.006 & 0.005 \\
\hline $\mathrm{LOI}_{525}$ & 8.1 & 8.5 & 2.3 & 5.4 \\
\hline $\mathrm{LOI}_{950}$ & 8.3 & 8.9 & 2.6 & 5.8 \\
\hline $\mathrm{Na} / \mathrm{Al}$ molar ratio & 1.1 & 0.6 & 1.1 & 0.7 \\
\hline
\end{tabular}

of $\mathrm{Na}_{2} \mathrm{O}$ was $41 \%$ and $35 \%$ lower in GP-AA and GP-H-AA samples compared with nonwashed samples GP and GP-H, respectively. The $\mathrm{Na} / \mathrm{Al}$ molar ratio was close to 1 in the GP and GP-H samples, which indicated that there was little excess sodium $(\mathrm{Na})$ in the geopolymers and that the heat treatment did not reduce the alkaline metal content. However, the amount of bromine $(\mathrm{Br})$ was $54 \%$ and $62 \%$ lower in samples GP-H and GP-H-AA, respectively, compared with the GP sample, which suggested that heat treatment had decreased the amount of CTAB. LOI $_{525}$ results (Table 1) supported this conclusion since the weight loss observed for samples GP and GP-AA was considerably higher than for samples GP-H and GP-H-AA. The higher LOI $_{525}$ result obtained for the GP-H-AA sample compared with GP-H is likely an outcome of the 
Table 2. Surface Areas, Average Pore Widths, And Pore Volumes of Geopolymer Foams Analyzed by BET-BJH

\begin{tabular}{cccc} 
& GP & GP-AA & GP-H \\
BET surface area $\left(\mathrm{m}^{2} / \mathrm{g}\right)$ & $32.33 \pm 0.11$ & $47.81 \pm 0.11$ & $33.14 \pm 0.06$ \\
average pore width $(\mathrm{nm})$ & 15.58 & 12.85 & 13.30 \\
macropore volume $\left(\mathrm{cm}^{3} / \mathrm{g}\right)^{a}$ & 0.0007 & 0.0006 & 0.0063 \\
mesopore volume $\left(\mathrm{cm}^{3} / \mathrm{g}\right)^{a}$ & 0.186 & 0.220 & 0.206 \\
micropore volume $\left(\mathrm{cm}^{3} / \mathrm{g}\right)^{a}$ & $4.5 \times 10^{-6}$ & $8.4 \times 10^{-4}$ & 0.0009 \\
${ }^{a}$ Macropores: $d_{0}>50 \mathrm{~nm}$, mesopores: $2 \mathrm{~nm} \leq d_{0} \leq 50 \mathrm{~nm}$, and micropores: $d_{0}<2 \mathrm{~nm}$ & 0.179 \\
\hline
\end{tabular}

residual acetic acid or sodium acetate in the sample. The low amount of bromine in the GP-AA sample can be explained by the sample preparation method and uncertainty of the analysis since the $\mathrm{LOI}_{525}$ value is in line with the result obtained for the GP sample (Figure S4).

The acetic acid wash increased the surface area and decreased the pore width of both the GP and GP-H samples (Table 2), which indicated that the acetic acid caused slight etching of the samples by removing unreacted $\mathrm{NaOH}$. In addition, the increase in surface area was more pronounced with samples that were not heat-treated, which can possibly be explained by the higher levels of nonreacted $\mathrm{NaOH}$ present in the matrix. On the basis of the $\mathrm{BJH}$ pore volume determinations, all samples were mostly mesoporous ${ }^{62}$ (Table 2, Figure S5). The total porosities of samples GP and GP-H were 93.3 and 93.0\%, respectively (GP-AA and GP-HAA were not analyzed because they were fixed in the columns).

Recently, the pore size distribution of a geopolymer foam produced using a very similar mix design to ours (i.e., direct foaming using CTAB and $\mathrm{H}_{2} \mathrm{O}_{2}$, Table $\mathrm{S} 1$ ) was analyzed by Xray microtomography and $\mathrm{BET} / \mathrm{BJH} .{ }^{63}$ The average pore width, surface area, and pore volume determined by BET were $11.7 \mathrm{~nm}, 31.0 \mathrm{~m}^{2} / \mathrm{g}$, and $0.139 \mathrm{~cm}^{3} / \mathrm{g}$, respectively. These results correspond well to our results presented in Table 2 . However, when the same sample was analyzed by X-ray microtomography, pore size distribution of $10-850 \mu \mathrm{m}$ was observed, with the average pore width of $0.399 \pm 0.221 \mathrm{~mm}$. The reason for the different results is that microtomography can detect pore sizes $>\sim 10 \mu \mathrm{m}$, while the BET/BJH method is able to detect pore sizes $<300 \mathrm{~nm}$. In the same study ${ }^{63}$ the porosities of geopolymer foams determined by X-ray microtomography and gas pycnometer were compared. The total and closed porosities determined with X-ray microtomography were $71.8 \%$ and $1 \%$, respectively, which was a clear indication of the interconnectivity of the pores. The open ( total) porosity determined with gas pycnometer $(88.8 \%)$ was close to values obtained in this study for samples GP and GP-H. The result was higher than that which was acquired using $\mathrm{X}$-ray microtomography, because of the presence of pores $<10 \mu \mathrm{m}$.

In summary, the different pretreatments were successful in altering the properties of the GPs. Acid wash reduced the alkalinity and increased the surface area of the samples, while annealing reduced the amount of $\mathrm{CTAB}$ on the samples. Considering the similarities in the mix design and in the results of the current and previous research, it can be assumed that the geopolymer foams were highly porous and had interconnected pores. The largest pores in our samples were approximately 1 $\mathrm{mm}$ in diameter (Figure S3), which indicates that the pore size ranged from $\sim 10 \mathrm{~nm}$ to $1 \mathrm{~mm}$.

3.2. Characteristics of CNCs. According to EFTEM images (Figure 3), the CNCs consisted of rod-like nanoparticles. The CNCs had a width distribution in the range of 5-17 nm, which is comparable to the result obtained for birch
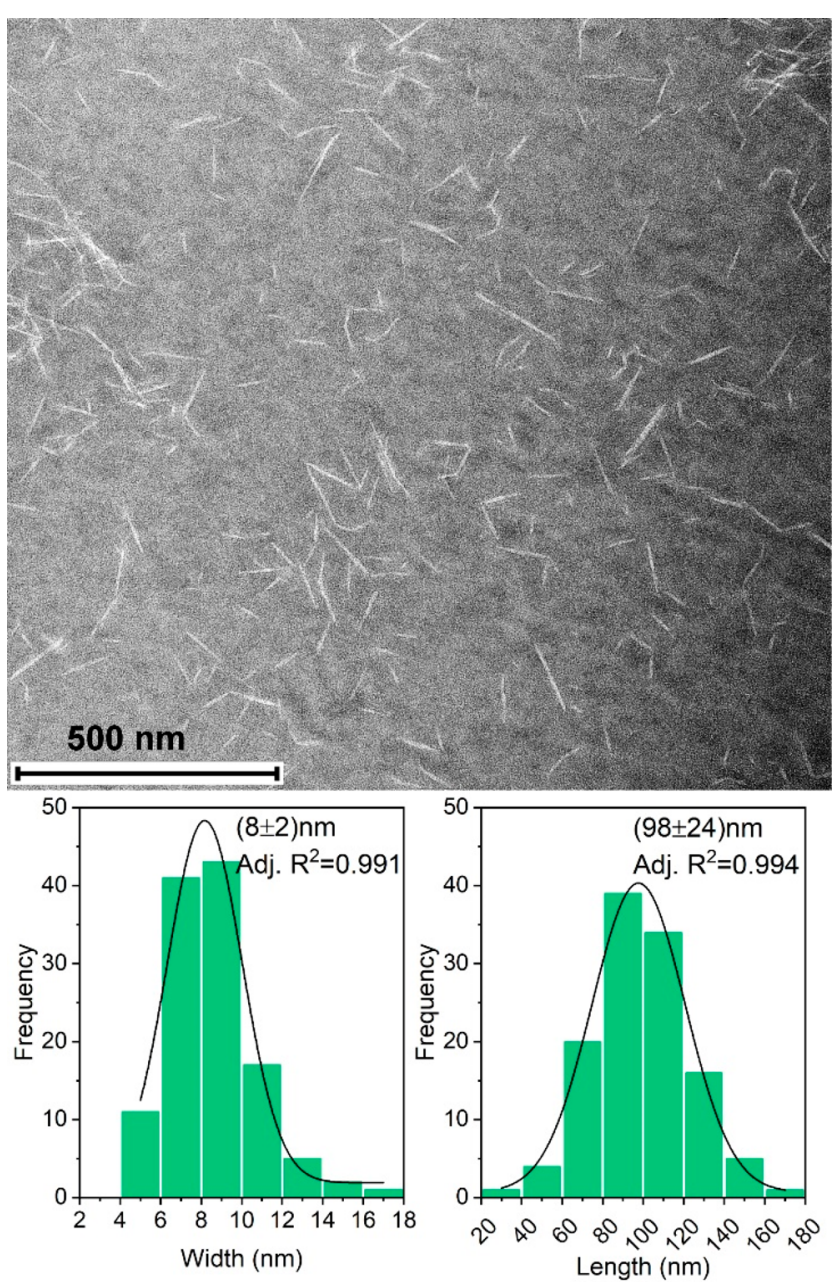

Figure 3. Energy-filtered transmission electron microscope (EFTEM) image of cellulose nanocrystals, and the width and length distributions. Gaussian fitting $(n=120)$ was used to evaluate the peak centers.

pulp $(5.7 \pm 1.3 \mathrm{~nm})$ under the same conditions. ${ }^{34}$ The length distribution ranged from $30-170 \mathrm{~nm}$. The average cationic charge density of CNCs was 2.4-3 mequiv/g in the $\mathrm{pH}$ range of 3-9 (Figure 4A), which is in line with previously reported results. ${ }^{34}$ The slight decrease in the charge density in $\mathrm{pH} 10$ is likely attributed to $\beta$-alkoxy fragmentation of the dialdehyde cellulose backbone in alkaline conditions and/or deprotonation of the functional groups (guanidinium ions). ${ }^{64,65}$ The DRIFT spectra (Figure 4B) confirmed the success of the chemical functionalization in both synthesis steps. The spectrum of DAC (the product of step 1) exhibited a band at $1731 \mathrm{~cm}^{-1}$, which is characteristic of an aldehyde carbonyl group. In contrast, the spectrum of CDAC (the product of step 2) had a band at $1680 \mathrm{~cm}^{-1}$ attributed to $\mathrm{C}=\mathrm{N}$ bond vibration 
A

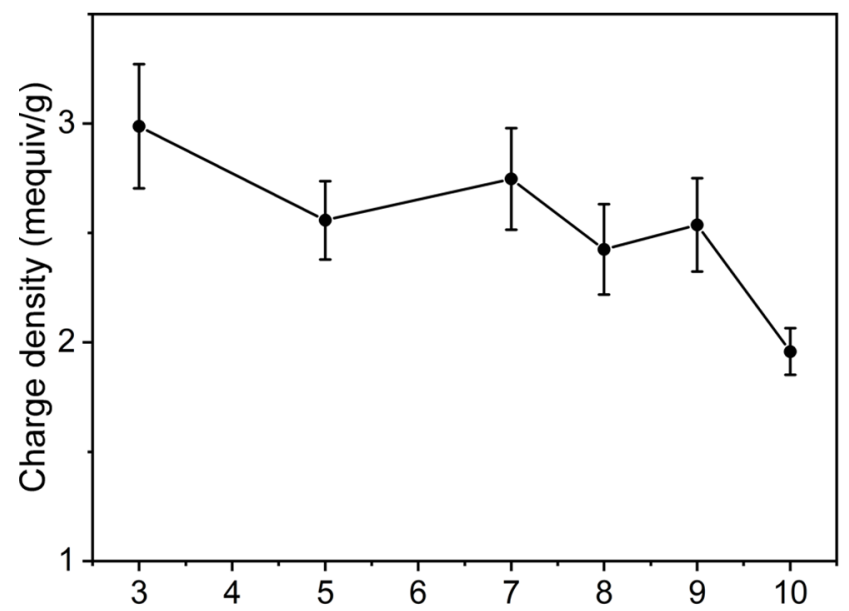

B $\mathrm{pH}$

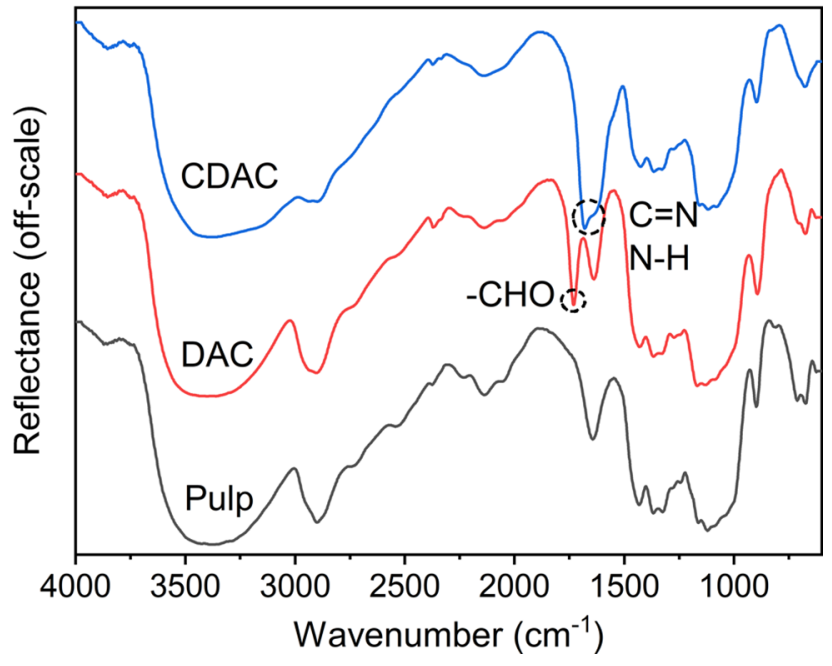

Figure 4. (A) Charge density of cellulose nanocrystals as a function of $\mathrm{pH}$. The error bars represent the sample standard deviation $(n=12)$. (B) Diffuse reflectance infrared Fourier transform (DRIFT) spectra of cellulose pulp, dialdehyde cellulose (DAC), and cationized dialdehyde cellulose (CDAC).

and a shoulder band at $\sim 1642 \mathrm{~cm}^{-1}$ attributed to $\mathrm{N}-\mathrm{H}$ bond bending. 6,67

3.3. Preparation of CNC-Geopolymer Hybrid Foams. Acid-washed samples GP-AA and GP-H-AA were selected for surface modification with cationic $\mathrm{CNCs}$ and application testing in dye removal. Especially, it was addressed, if the heat treatments (hydrothermal and annealing) had altered the surface properties of the geopolymer foam, and thus had an impact on the surface modification and dye adsorption compared with the nonheat-treated sample. A good permeability to the dilute CNC suspension was expected as GP and GP-H samples had very high total porosities $(93.3 \%$ and 93.0\%, respectively). The amount of CNC retained onto the geopolymers increased steadily, reaching $11-18 \mathrm{mg} / \mathrm{g}$ GP (243-346 mg, corresponds to $40-58 \%$ of $\mathrm{CNC}$ ) during the 6 days of treatment (Figure 5). The average surface coverages of GP-AA-CNC and GP-H-AA-CNC were $2.2 \%$ and $3.4 \%$, respectively (the parameters and calculation steps are presented in Table S2). The maximum theoretical surface coverage would have been $7.2 \%$, with the assumption that all CNCs $(0.6 \mathrm{~g})$ had adsorbed on the geopolymer. Possible
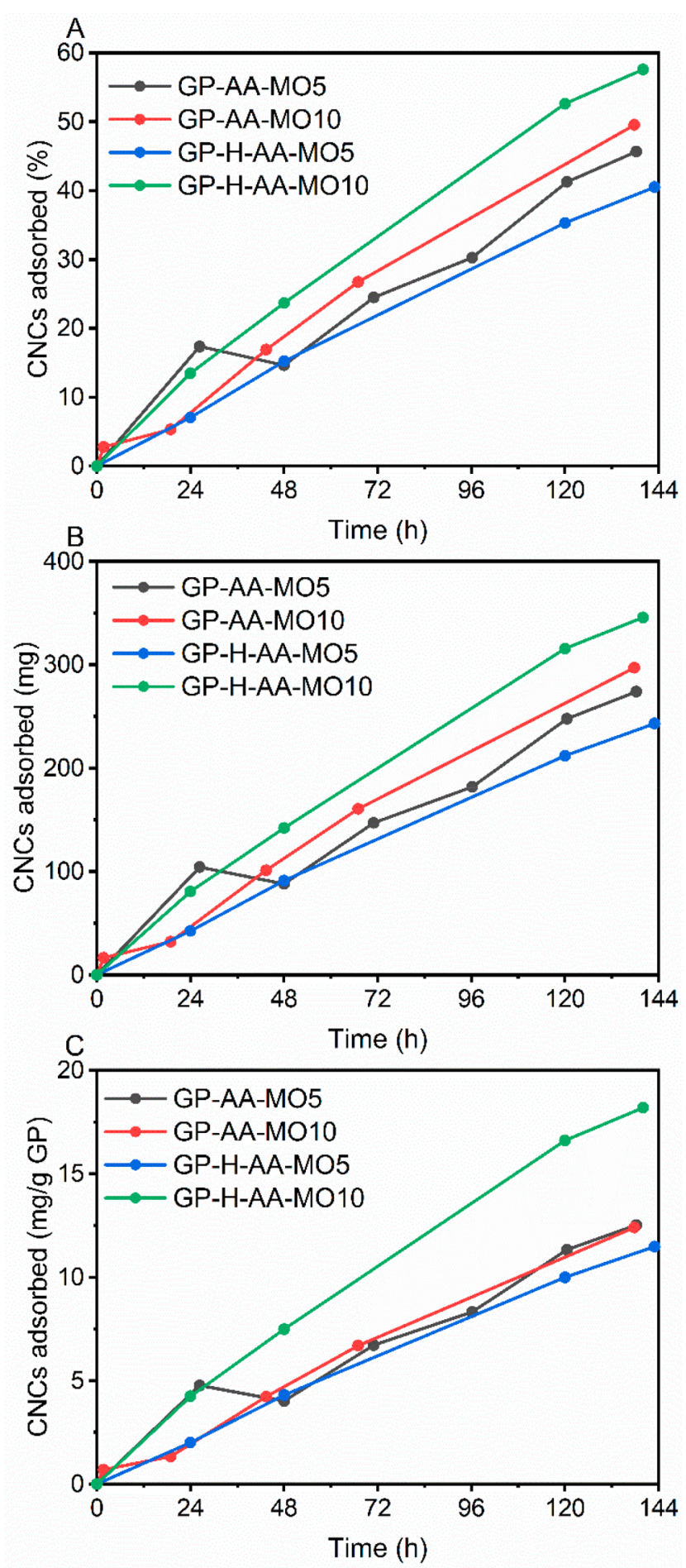

Figure 5. Portion of cellulose nanocrystals (CNCs) adsorbed (A:\%; $\mathrm{B}: \mathrm{mg}$; C: $\mathrm{mg}$ per $1 \mathrm{~g}$ of geopolymer) as a function of contact time onto the acid-washed geopolymer (GP-AA) and heat-treated acidwashed geopolymer (GP-H-AA) samples. MO5 and MO10 refer to the methyl orange concentrations in the consecutive dye removal experiments.

reasons for the observed lower surface coverages are the setup used for the combination (flow instead of sinking), insufficient surface charges on CNCs and geopolymers, and size exclusion. On the basis of the BET/BJH analysis (Table 2), the geopolymers were mainly mesoporous $(2-50 \mathrm{~nm})$ with the average pore width of $\sim 11-13 \mathrm{~nm}$. On the basis of the 
EFTEM image analysis CNCs had a width distribution of 5$17 \mathrm{~nm}$ (Figure 3), which indicated that the surface modification of the smallest pores of the geopolymers was rather unlikely. It can be deduced that CNCs covered the macropores $(>50 \mathrm{~nm})$, but because the geopolymer foam was mainly mesoporous, the total surface coverage remained low.

The slightly higher surface coverage of GP-H-AA sample compared with GP-AA sample is mainly attributed to the lower BET surface area of GP-H-AA sample (Table 2), because the amount of $\mathrm{CNCs}$ retained in the geopolymers was not significantly different (Figure 5). Higher surface coverage values could be achieved by increasing the dry matter content of the CNC suspension, but then again, the risk of blockage of the pores and the cake formation on the surface of the monolith increases, as well as the total costs of the process.

The CNC adsorption and surface coverage results implied that the geopolymer surfaces interacted in a similar manner with CNCs despite the different pretreatments and suggested that the geopolymer possessed an opposite surface charge to that of CNCs. This was confirmed with the $\zeta$-potential result of geopolymers (Figure 6). Both samples had an anionic

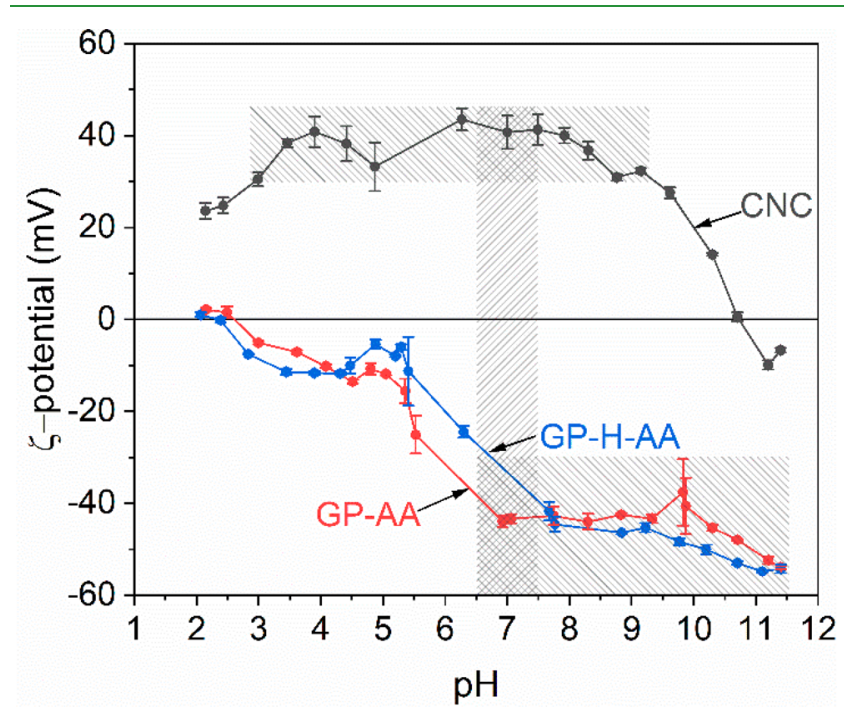

Figure 6. $\zeta$-Potentials of cellulose nanocrystals (CNCs), acid-washed geopolymers (GP-AA) and heat-treated acid washed geopolymers (GP-H-AA) as a function of $\mathrm{pH}$. Each data point represents an average value of three measurements together with the sample standard deviation. The vertical shaded area highlights the $\mathrm{pH}$ range during the CNC-GP combination, and the horizontal shaded areas highlight the $\mathrm{pH}$ regions where particles form stable colloidal systems.

surface charge in the $\mathrm{pH}$ range of 3-11.5 and point of zero charge (PZC) at $\mathrm{pH} 2.5$ (Figure 6). The samples exhibited a similar behavior where the anionic charge increased steeply (i.e., became more anionic) above $\mathrm{pH} 5$ and stabilized at $\mathrm{pH}$ 6.9 and 7.7 in the case of GP-AA and GP-H-AA samples, respectively. The results are in line with the results obtained previously for metakaolin geopolymer monoliths, ${ }^{24}$ where a negative surface charge in $\mathrm{pH} 2-12$ and charge stabilization at $\mathrm{pH}>5.6$ was observed.

The $\zeta$-potential of CNCs (Figure 6) was in turn consistent with the charge density result (Figure 4A), indicating that $\mathrm{CNCs}$ had a stable cationic charge in $\mathrm{pH}$ range $3-9.5$ ( $\zeta$ potential $>+30 \mathrm{mV}$, shaded horizontal area in Figure 6). The $\mathrm{PZC}$ was at $\mathrm{pH} \approx 10.5$. The $\mathrm{pH}$ of the $\mathrm{CNC}$ solution decreased from the original value of 7.5 to $6.8-7.0$ during the surface modification of the geopolymer, presumably due to the residual acetic acid in the geopolymer. As can be seen from Figure 6 (shaded vertical area), the CNCs and both geopolymer samples exhibited high cationic and anionic surface charges in this region, respectively. The higher initial $\mathrm{pH}$ (e.g., 7.6-8) of the CNC solution was not suitable, evident as CNCs precipitated when brought into contact with geopolymers. This may be because small particles were released from the geopolymer foam as a result of the fluid flow and fastening of the caps (containing liquid inlet and outlet, Figure 1D), and these highly charged ( $\zeta$-potential -45 $\mathrm{mV}$, Figure 6) particles neutralized the cellulose nanoparticles in the solution in this $\mathrm{pH}$ region (the $\mathrm{CNC}$ suspension is stable at $\mathrm{pH} 8$, Figure $4 \mathrm{~A}$ ). At $\mathrm{pH}>8$, the appearance of the CNC solution changed (e.g., bubbling, yellowing) when in contact with geopolymers, which is likely caused by the degradation of dialdehyde cellulose backbone in alkaline conditions. ${ }^{64}$

Geopolymer surface modification by CNCs was confirmed by FESEM (Figure 7). Individual rod-like CNCs formed a fibrous, assembled nanoscale network in both GP-AA and GP$\mathrm{H}$-AA samples, as also supported by the CNC surface coverage (adsorption) results (Figure 5). As the FESEM samples were taken from filtration columns that had already been used in dye removal experiments, the CNCs were noted to be fixed on the surfaces and pores of the geopolymer by strong electrostatic forces. On the basis of the FESEM images, the CNCs existed in two different forms on the geopolymer surfaces. First, CNCs had arranged into long filaments that spread across the pores (Figure 7A2 and 7B2). Second, CNCs formed a film (i.e., CNCs lying flat on the surface), evidenced by shrunken and broken CNC layers seen across the samples (Figures 7A3, A4, $\mathrm{B} 3$, and B4). On the basis of the FESEM images the films were not uniform and they had a multilayer structure with an approximate thickness of tens to hundreds of $\mathrm{nm}$ (the width distribution of individual CNCs was 5-17 nm, Figure 3). Both filament and film formation are typical for CNCs. ${ }^{68,69}$ It seemed that $\mathrm{CTAB}$, despite being cationic, did not hinder the surface modification of the geopolymers by cationic CNCs. One possible explanation for this is the prolonged contact between $\mathrm{CNCs}$ and the geopolymer, which enabled the CNC particles to find the optimum location (i.e., the absence of $\mathrm{CTAB})$ to attach onto.

The geopolymers were observed to retain 1.9-2.4 g of water per $1 \mathrm{~g}$ of geopolymer that originated either from the washing step (GP-AA and GP-H-AA samples) or from the dilute CNC suspension (GP-AA-CNC and GP-H-AA-CNC samples). This can be explained by the high surface area and porosity of the geopolymers (Table 2). Despite being hydrophilic, the addition of CNCs on the geopolymer surface did not improve the water retention capacity, possibly because of their rod-like morphology (Figure 3) and the fact that they were scattered across the geopolymer surfaces, which prevented the hydrogel formation.

3.4. Utilization of CNC Modified Geopolymer Hybrid Foams As Reactive Filter Media for Anionic Dye Removal. Decoration of the large internal surface of the geopolymer with cationic CNCs improved the anionic dye removal efficiency at $\mathrm{pH} 7$ compared with the geopolymer samples without CNCs (Figure 8) in the filtration tests. The initial dye concentration ( 5 and $10 \mathrm{mg} / \mathrm{L}$ ) did not have a significant impact on the removal. The increase in the dye removal caused by the addition of CNCs was clearly more pronounced in the heat-treated samples GP-H-AA-CNC $\left(C_{0}=\right.$ 

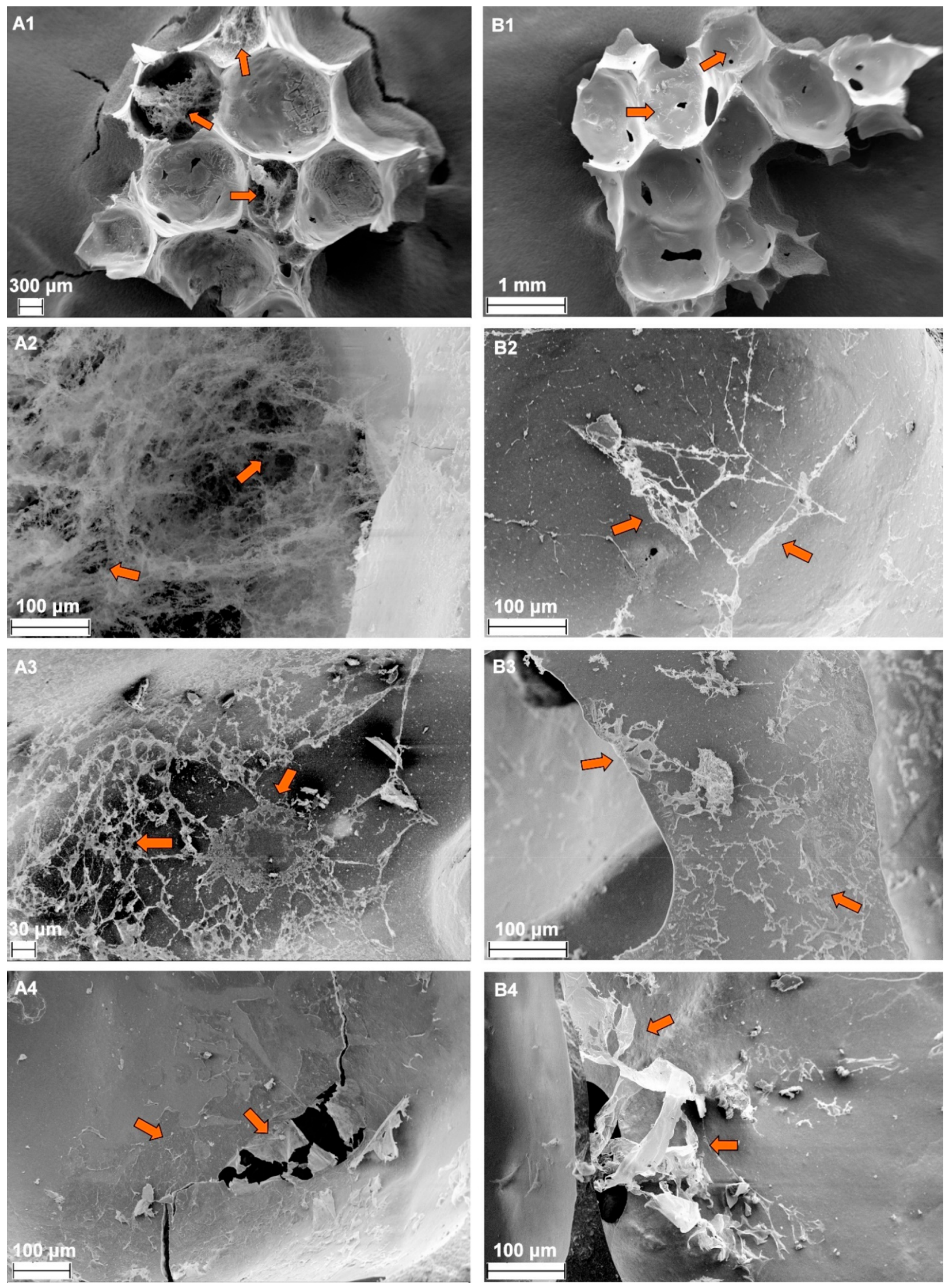

Figure 7. Field emission scanning electron microscope (FESEM) images of (A1-A4) acid-washed geopolymer foams modified with cellulose nanocrystals (GP-AA-CNC) and (B1-B4) heat-treated acid-washed geopolymer foams modified with cellulose nanocrystals (GP-H-AA-CNC) with different magnifications. Arrows mark the locations of the CNCs. 

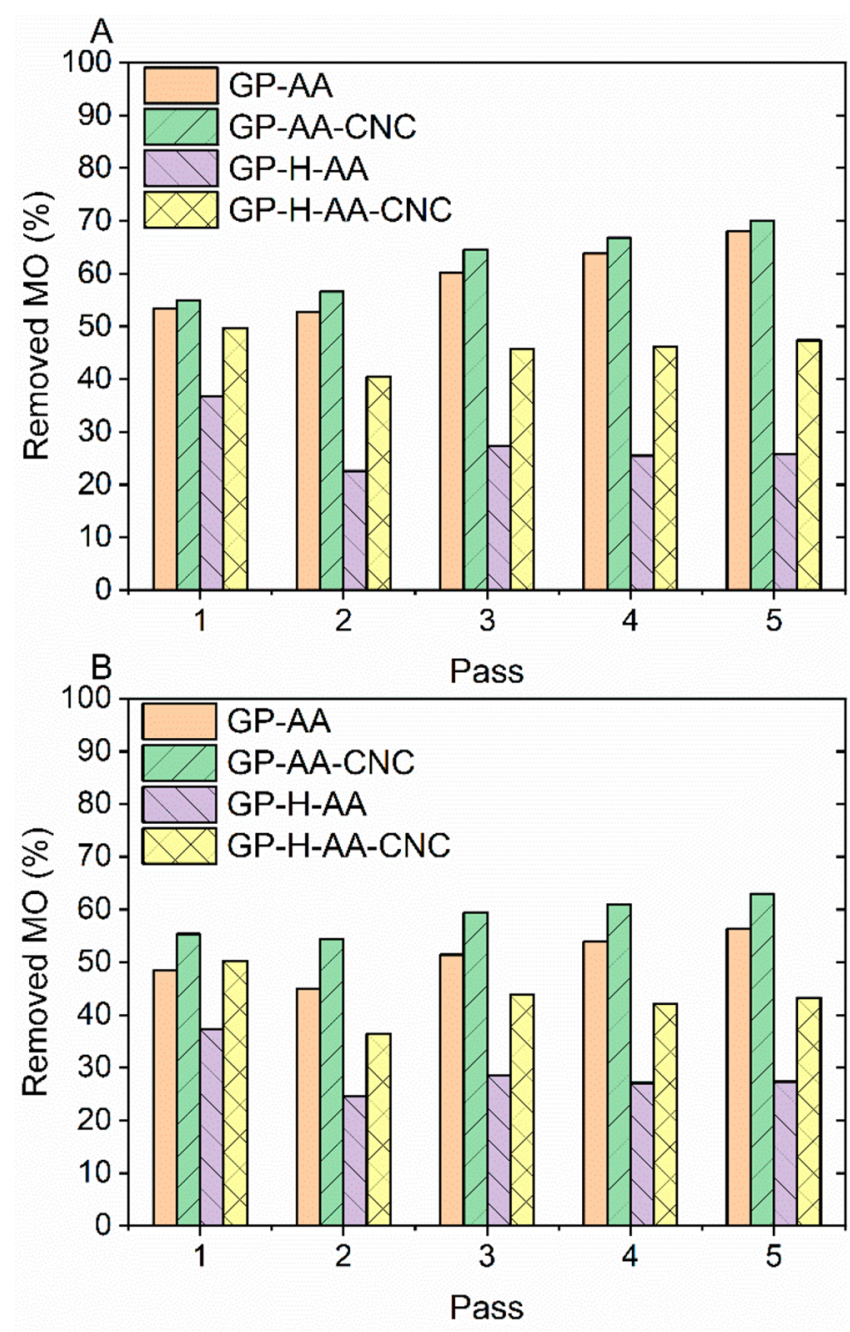

Figure 8. Methyl orange (MO) removal as a function of the number of passes through the acid-washed geopolymer (GP-AA) and heattreated acid-washed (GP-H-AA) geopolymer columns with and without cellulose nanocrystals (CNCs) at $\mathrm{pH} 7$ using an initial $\mathrm{MO}$ concentration of (A) $5 \mathrm{mg} / \mathrm{L}$ and (B) $10 \mathrm{mg} / \mathrm{L}$.

$\left.5 \mathrm{mg} / \mathrm{L}:+35-84 \% ; C_{0}=10 \mathrm{mg} / \mathrm{L}:+35-58 \%\right)$ than with nonheat-treated samples GP-AA-CNC $\left(C_{0}=5 \mathrm{mg} / \mathrm{L}:+3-\right.$ $\left.7 \% ; C_{0}=10 \mathrm{mg} / \mathrm{L}:+12-21 \%\right)$. Surprisingly, the total $\mathrm{MO}$ removal was higher with the nonheat-treated samples (with and without CNCs) than with the thermally treated samples $\left(C_{0}=5 \mathrm{mg} / \mathrm{L}:\right.$ GP-AA 53-68\%, GP-AA-CNC 55-70\%, GPH-AA 23-37\%, GP-H-AA-CNC 40-50\%; $C_{0}=10 \mathrm{mg} / \mathrm{L}: \mathrm{GP}-$ AA 45-56\%, GP-AA-CNC 54-63\%, GP-H-AA 25-37\%, GPH-AA-CNC 36-50\%).

The initial hypothesis was that the major constituents responsible for MO adsorption would be CNCs, but, on the basis of these results, it is likely that CTAB also participated in the adsorption. CTAB is a cationic surfactant (Figure 1A) that was added to stabilize the liquid-gas interface during the geopolymer foam synthesis. Considering this, it can be assumed that $\mathrm{CTAB}$ was located on the surfaces of the pores across the samples. Thus, the increased dye removal results obtained using the nonheat-treated samples (GP-AA and GPAA-CNC) can be largely explained by the presence of CTAB as the XRF and LOI results (Table 1) indicated that the nonheat-treated samples contained more $\mathrm{CTAB}$ than the heattreated ones. One possible reason why the addition of CNCs did not significantly improve the dye removal results with the nonheat-treated samples (although being present, see section 3.3) is that the CTAB located on the surfaces of the pores hindered the attachment of CNCs on those surfaces and assisted the aggregation of CNCs instead of a film formation. This aggregation, in turn, lowered the amount of available functional groups in the CNCs for dye adsorption.

In contrast, in the heat-treated samples, CNCs were mainly responsible for the $\mathrm{MO}$ adsorption as the amount of $\mathrm{CTAB}$ in the geopolymers was reduced. This also explained the low dye removal efficiency of the GP-H-AA samples as they contained no CNCs and only a low amount of CTAB.

In Figure 8, the dye removal efficiency is presented as a function of the passes of the same solution through the filtration column. The trends were different between the two geopolymer samples. For the GP-AA samples (with and without $\mathrm{CNCs}$ ), the trend followed the anticipated pattern, i.e., the dye removal increased after each pass, indicating that more and more dye was adsorbed onto the filter. With the GP-H-AA samples, however, there was a decrease in the removal efficiency after the first pass, after which it increased slightly and then stabilized. This phenomenon was visible for samples with and without CNCs and in both dye concentrations. A possible explanation for the observed behavior is the $\zeta$ potential of geopolymers (Figure 6). GP-H-AA particles reached stability at $\mathrm{pH} 7.7$, implying that, at $\mathrm{pH} 7$ (the initial $\mathrm{pH}$ of the dye solution), the surface charge of the geopolymer was not anionic enough to retain cationic CNCs which had impact on the dye removal. Thus, GP-H-AA filters are expected to perform better at $\mathrm{pH}>7.7$. For the GP-AA samples, this phenomenon did not occur because the particles had already reached stability at $\mathrm{pH}$ 6.9.

One issue that needs further assessment is to investigate how firmly CNCs were attached to the geopolymer surfaces since CNCs were observed in the UV-vis spectra after the filtration cycles (Figure S6 and S7, $\lambda=200-300 \mathrm{~nm}$ ). On the basis of the UV-vis spectra intensities, more CNCs were detached from the nonheat-treated geopolymer samples (Figures S6B and S7B) than from heat-treated ones (Figures S6D and S7D), which is a result of the presence of CTAB in the geopolymer structure. However, CNCs were also found in the filtrates of the heat-treated samples. Therefore, future work should focus on improving the attachment of CNCs on the surfaces, e.g., through silane chemistry. ${ }^{70,71}$ This is especially crucial for the column filtration applications where a continuous flow is applied. Another point to consider in future work is the leaching of the surfactant from the geopolymer as surfactants can have a negative impact on the environment. ${ }^{31}$ An alternative approach would be to use biobased surfactants (e.g., egg white ${ }^{72}$ ).

A compressive strength of $\sim 0.6 \mathrm{MPa}$ (at $7 \mathrm{~d}$ age) has been reported for a geopolymer foam produced using a very similar mix design to ours (Table S1). ${ }^{63}$ In comparison, sintered ceramic water treatment filters with similar porosities have compressive strengths of approximately $0.9-1.7 \mathrm{MPa} .^{73-75}$ Considering this background and the fact that our design was almost identical to the reported one, it can be assumed that our filter material has sufficient mechanical properties for the intended application. However, these properties should be studied in detail in the future works. Finally, a more detailed adsorption study (the effect of $\mathrm{pH}$, temperature, time, adsorbent concentration, adsorbate concentration, desorption, and regeneration) should be conducted to gain a full 
understanding of the potential of these novel hybrid foam materials.

\section{CONCLUSIONS}

The surfaces of the cured geopolymer foams were successfully modified with cationic CNCs after a mild acid-wash treatment. CNCs attached to the geopolymer surfaces through electrostatic interactions and were aligned as continuous films and filaments across the samples. It was found that the addition of $\mathrm{CNCs}$ to the geopolymers improved the anionic dye removal by up to $84 \%$ in a filtration setup compared with samples without CNCs. In addition, the cationic surfactant $\mathrm{CTAB}$ had a crucial role in dye removal: When both $\mathrm{CTAB}$ and $\mathrm{CNCs}$ were simultaneously present in the geopolymer, $\mathrm{CTAB}$ was mostly responsible for the dye adsorption. However, when the amount of $\mathrm{CTAB}$ in the geopolymer foam was reduced through heat treatment before CNCs were incorporated on the surface, CNCs significantly increased dye removal. This work demonstrated how the properties of inorganic foams and organic nanomaterials, i.e., rigidity, high porosity and ion exchange capacity of the inorganic foam, and high surface area and functionality of the organic nanoparticles, can be successfully combined to increase the dye removal.

\section{ASSOCIATED CONTENT}

\section{(s) Supporting Information}

The Supporting Information is available free of charge at https://pubs.acs.org/doi/10.1021/acsami.0c05927.

Photographs of the set-ups used in the CNC filtration and $\mathrm{MO}$ removal experiments, $\mathrm{MO}$ calibration curve and spectra, FESEM images and photographs of the geopolymer samples, TGA curves of the geopolymer samples, incremental and cumulative pore volumes of the geopolymer samples, table comparing the mix designs of geopolymer foams, table of parameters used for the surface coverage calculation, and UV-vis spectra of MO solutions after column filtrations (PDF)

\section{AUTHOR INFORMATION}

\section{Corresponding Author}

Henrikki Liimatainen - Fiber and Particle Engineering Research Unit, University of Oulu, FI-90014 Oulu, Finland; (1) orcid.org/0000-0002-7911-2632;

Phone: +358505659711; Email: henrikki.liimatainen@ oulu.fi

\section{Authors}

Tuula Selkälä - Fiber and Particle Engineering Research Unit, University of Oulu, FI-90014 Oulu, Finland; orcid.org/ 0000-0001-8575-5848

Terhi Suopajärvi - Fiber and Particle Engineering Research Unit, University of Oulu, FI-90014 Oulu, Finland

Juho Antti Sirviö - Fiber and Particle Engineering Research Unit, University of Oulu, FI-90014 Oulu, Finland; (1) orcid.org/0000-0002-7404-3340

Tero Luukkonen - Fiber and Particle Engineering Research Unit, University of Oulu, FI-90014 Oulu, Finland; (1) orcid.org/0000-0002-1124-775X

Paivo Kinnunen - Fiber and Particle Engineering Research Unit, University of Oulu, FI-90014 Oulu, Finland
Ana Luiza Coelho Braga de Carvalho - Clausthal Technical University, Department of Mineral and Waste Processing, 38678 Clausthal-Zellerfeld, Germany

Complete contact information is available at: https://pubs.acs.org/10.1021/acsami.0c05927

\section{Author Contributions}

The manuscript was written through contributions of all authors.

\section{Funding}

Support from the Advanced Materials Doctoral Program of the University of Oulu Graduate School and the Bionanochemicals project of the Academy of Finland (327810) is acknowledged. P.K. acknowledges financial support from Academy of Finland (grants 322085 and 326291).

Notes

The authors declare no competing financial interest.

\section{ACKNOWLEDGMENTS}

Ville Karvonen is acknowledged for his assistance in CNC syntheses and characterizations, Harisankar Sreenivasan for his help with the geopolymer mix design, Kasper Hahtonen for providing the molds and column filtration setup, Jonne Ukkola for his engineering advice, Elisa Wirkkala for her assistance in the geopolymer grinding, Jarno Karvonen for performing the XRF and LS measurements, and Kaisu Ainassaari for performing the BET-BJH measurements. Part of the work was carried out with the support of the Center of Microscopy and Nanotechnology, University of Oulu, Finland.

\section{REFERENCES}

(1) Ge, Z.; Chen, H.; Ren, Y.; Xiao, P.; Yang, Y.; Zhang, T.; Ma, Y.; Chen, Y. A Universal Method for the Preparation of Dual Network Reduced Graphene Oxide-Ceramic/Metal Foam Materials with Tunable Porosity and Improved Conductivity. Chem. Mater. 2018, 30 (22), 8368-8374.

(2) Ressnig, D.; Antonietti, M. Ultrafast Syntheses of Silver Foams from $\mathrm{Ag}_{2} \mathrm{NCN}$ : Combustion Synthesis versus Chemical Reduction. Chem. Mater. 2014, 26 (14), 4064-4067.

(3) Peng, Y.; Liu, H.; Li, T.; Zhang, J. Hybrid Metallic Foam with Superior Elasticity, High Electrical Conductivity, and Pressure Sensitivity. ACS Appl. Mater. Interfaces 2020, 12 (5), 6489-6495.

(4) Xiao, K.; Ding, L.-X.; Liu, G.; Chen, H.; Wang, S.; Wang, H. Freestanding, Hydrophilic Nitrogen-Doped Carbon Foams for Highly Compressible All Solid-State Supercapacitors. Adv. Mater. 2016, 28 (28), 5997-6002.

(5) Zeng, X.; Ye, L.; Yu, S.; Sun, R.; Xu, J.; Wong, C.-P. Facile Preparation of Superelastic and Ultralow Dielectric Boron Nitride Nanosheet Aerogels via Freeze-Casting Process. Chem. Mater. 2015, 27 (17), 5849-5855.

(6) Wang, X.-B.; Jiang, X.-F.; Bando, Y. Blowing Route towards Advanced Inorganic Foams. Bull. Chem. Soc. Jpn. 2019, 92 (1), 245263.

(7) Gibson, L. J.; Ashby, M. F. Introduction. In Cellular Solids: Structure and Properties; Cambridge Solid State Science Series; Cambridge University Press: Cambridge, 1997; pp 1-14 DOI: $10.1017 / \mathrm{CBO} 9781139878326.003$.

(8) Jiang, S.; Agarwal, S.; Greiner, A. Low-Density Open Cellular Sponges as Functional Materials. Angew. Chem., Int. Ed. 2017, 56 (49), 15520-15538.

(9) Novais, R. M.; Pullar, R. C.; Labrincha, J. A. Geopolymer Foams: An Overview of Recent Advancements. Prog. Mater. Sci. 2020, 109, 100621.

(10) Kränzlein, E.; Pöllmann, H.; Krcmar, W. Metal Powders as Foaming Agents in Fly Ash Based Geopolymer Synthesis and Their 
Impact on the Structure Depending on the Na / Al Ratio. Cem. Concr. Compos. 2018, 90, 161-168.

(11) Novais, R. M.; Buruberri, L. H.; Seabra, M. P.; Labrincha, J. A. Novel Porous Fly-Ash Containing Geopolymer Monoliths for Lead Adsorption from Wastewaters. J. Hazard. Mater. 2016, 318, 631-640.

(12) Bai, C.; Conte, A.; Colombo, P. Open-Cell Phosphate-Based Geopolymer Foams by Frothing. Mater. Lett. 2017, 188, 379-382.

(13) Rasouli, H. R.; Golestani-Fard, F.; Mirhabibi, A. R.; Nasab, G. M.; Mackenzie, K. J. D.; Shahraki, M. H. Fabrication and Properties of Microporous Metakaolin-Based Geopolymer Bodies with Polylactic Acid (PLA) Fibers as Pore Generators. Ceram. Int. 2015, 41 (6), 7872-7880.

(14) Papa, E.; Medri, V.; Benito, P.; Vaccari, A.; Bugani, S.; Jaroszewicz, J.; Swieszkowski, W.; Landi, E. Synthesis of Porous Hierarchical Geopolymer Monoliths by Ice-Templating. Microporous Mesoporous Mater. 2015, 215, 206-214.

(15) Franchin, G.; Scanferla, P.; Zeffiro, L.; Elsayed, H.; Baliello, A.; Giacomello, G.; Pasetto, M.; Colombo, P. Direct Ink Writing of Geopolymeric Inks. J. Eur. Ceram. Soc. 2017, 37 (6), 2481-2489.

(16) Medpelli, D.; Seo, J.-M.; Seo, D.-K. Geopolymer with Hierarchically Meso-/Macroporous Structures from Reactive Emulsion Templating. J. Am. Ceram. Soc. 2014, 97 (1), 70-73.

(17) Provis, J. L.; Van Deventer, J. S. J. 1-Introduction to Geopolymers. In Geopolymers; Provis, J. L., van Deventer, J. S. J., Eds.; Woodhead Publishing Series in Civil and Structural Engineering; Woodhead Publishing, 2009; pp 1-11. DOI: 10.1533/ 9781845696382.1.

(18) Barbosa, V. F. F.; MacKenzie, K. J. D.; Thaumaturgo, C. Synthesis and Characterisation of Materials Based on Inorganic Polymers of Alumina and Silica: Sodium Polysialate Polymers. Int. J. Inorg. Mater. 2000, 2 (4), 309-317.

(19) Singh, N. B.; Middendorf, B. Geopolymers as an Alternative to Portland Cement: An Overview. Construction and Building Materials 2020, 237, 117455.

(20) Luukkonen, T.; Heponiemi, A.; Runtti, H.; Pesonen, J.; Yliniemi, J.; Lassi, U. Application of Alkali-Activated Materials for Water and Wastewater Treatment: A Review. Rev. Environ. Sci. Bio/ Technol. 2019, 18 (2), 271-297.

(21) Siyal, A. A.; Shamsuddin, M. R.; Khan, M. I.; Rabat, N. E.; Zulfiqar, M.; Man, Z.; Siame, J.; Azizli, K. A. A Review on Geopolymers as Emerging Materials for the Adsorption of Heavy Metals and Dyes. J. Environ. Manage. 2018, 224, 327-339.

(22) Novais, R. M.; Carvalheiras, J.; Tobaldi, D. M.; Seabra, M. P.; Pullar, R. C.; Labrincha, J. A. Synthesis of Porous Biomass Fly AshBased Geopolymer Spheres for Efficient Removal of Methylene Blue from Wastewaters. J. Cleaner Prod. 2019, 207, 350-362.

(23) Ge, Y.; Cui, X.; Liao, C.; Li, Z. Facile Fabrication of Green Geopolymer/Alginate Hybrid Spheres for Efficient Removal of $\mathrm{Cu}(\mathrm{II})$ in Water: Batch and Column Studies. Chem. Eng. J. 2017, 311, 126134.

(24) Novais, R. M.; Ascensão, G.; Tobaldi, D. M.; Seabra, M. P.; Labrincha, J. A. Biomass Fly Ash Geopolymer Monoliths for Effective Methylene Blue Removal from Wastewaters. J. Cleaner Prod. 2018, 171, 783-794.

(25) Hertel, T.; Novais, R. M.; Murillo Alarcón, R.; Labrincha, J. A.; Pontikes, Y. Use of Modified Bauxite Residue-Based Porous Inorganic Polymer Monoliths as Adsorbents of Methylene Blue. J. Cleaner Prod. 2019, 227, 877-889.

(26) Daughton, C. G.; Ternes, T. A. Pharmaceuticals and Personal Care Products in the Environment: Agents of Subtle Change? Environ. Health Perspect. 1999, 107, 907.

(27) Tkaczyk, A.; Mitrowska, K.; Posyniak, A. Synthetic Organic Dyes as Contaminants of the Aquatic Environment and Their Implications for Ecosystems: A Review. Sci. Total Environ. 2020, 717, 137222.

(28) Luo, Y.; Guo, W.; Ngo, H. H.; Nghiem, L. D.; Hai, F. I.; Zhang, J.; Liang, S.; Wang, X. C. A Review on the Occurrence of Micropollutants in the Aquatic Environment and Their Fate and
Removal during Wastewater Treatment. Sci. Total Environ. 2014, 473-474, 619-641.

(29) Rodriguez-Narvaez, O. M.; Peralta-Hernandez, J. M.; Goonetilleke, A.; Bandala, E. R. Treatment Technologies for Emerging Contaminants in Water: A Review. Chem. Eng. J. 2017, 323, 361-380.

(30) Salleh, M. A. M.; Mahmoud, D. K.; Karim, W. A. W. A.; Idris, A. Cationic and Anionic Dye Adsorption by Agricultural Solid Wastes: A Comprehensive Review. Desalination 2011, 280 (1-3), 113.

(31) Siyal, A. A.; Shamsuddin, M. R.; Rabat, N. E.; Zulfiqar, M.; Man, Z.; Low, A. Fly Ash Based Geopolymer for the Adsorption of Anionic Surfactant from Aqueous Solution. J. Cleaner Prod. 2019, 229, $232-243$.

(32) Köse, K.; Mavlan, M.; Youngblood, J. P. Applications and Impact of Nanocellulose Based Adsorbents. Cellulose 2020, 27, 2967.

(33) Selkälä, T.; Sirviö, J. A.; Lorite, G. S.; Liimatainen, H. Anionically Stabilized Cellulose Nanofibrils through Succinylation Pretreatment in Urea-Lithium Chloride Deep Eutectic Solvent. ChemSusChem 2016, 9 (21), 3074-3083.

(34) Li, P.; Sirviö, J. A.; Asante, B.; Liimatainen, H. Recyclable Deep Eutectic Solvent for the Production of Cationic Nanocelluloses. Carbohydr. Polym. 2018, 199, 219-227.

(35) Sirviö, J. A.; Ukkola, J.; Liimatainen, H. Direct Sulfation of Cellulose Fibers Using a Reactive Deep Eutectic Solvent to Produce Highly Charged Cellulose Nanofibers. Cellulose 2019, 26 (4), 23032316.

(36) Sirviö, J. A.; Visanko, M.; Liimatainen, H. Acidic Deep Eutectic Solvents As Hydrolytic Media for Cellulose Nanocrystal Production. Biomacromolecules 2016, 17 (9), 3025-3032.

(37) Li, P.; Sirviö, J. A.; Haapala, A.; Liimatainen, H. Cellulose Nanofibrils from Nonderivatizing Urea-Based Deep Eutectic Solvent Pretreatments. ACS Appl. Mater. Interfaces 2017, 9 (3), 2846-2855.

(38) Selkälä, T.; Suopajärvi, T.; Sirviö, J. A.; Luukkonen, T.; Lorite, G. S.; Kalliola, S.; Sillanpää, M.; Liimatainen, H. Rapid Uptake of Pharmaceutical Salbutamol from Aqueous Solutions with Anionic Cellulose Nanofibrils: The Importance of $\mathrm{PH}$ and Colloidal Stability in the Interaction with Ionizable Pollutants. Chem. Eng. J. 2018, 350, $378-385$.

(39) Selkälä, T.; Suopajärvi, T.; Sirviö, J. A.; Luukkonen, T.; Kinnunen, P.; Kling, K. I.; Wagner, J. B.; Liimatainen, H. Efficient Entrapment and Separation of Anionic Pollutants from Aqueous Solutions by Sequential Combination of Cellulose Nanofibrils and Halloysite Nanotubes. Chem. Eng. J. 2019, 374, 1013-1024.

(40) Karzar Jeddi, M.; Laitinen, O.; Liimatainen, H. Magnetic Superabsorbents Based on Nanocellulose Aerobeads for Selective Removal of Oils and Organic Solvents. Mater. Des. 2019, 183, 108115.

(41) Zhu, L.; Zong, L.; Wu, X.; Li, M.; Wang, H.; You, J.; Li, C. Shapeable Fibrous Aerogels of Metal-Organic-Frameworks Templated with Nanocellulose for Rapid and Large-Capacity Adsorption. ACS Nano 2018, 12 (5), 4462-4468.

(42) Szechyńska-Hebda, M.; Marczyk, J.; Ziejewska, C.; Hordyńska, N.; Mikuła, J.; Hebda, M. Optimal Design of PH-Neutral Geopolymer Foams for Their Use in Ecological Plant Cultivation Systems. Materials 2019, 12 (18), 2999.

(43) Szechyńska-Hebda, M.; Marczyk, J.; Ziejewska, C.; Hordyńska, N.; Mikuła, J.; Hebda, M. Neutral Geopolymer Foams Reinforced with Cellulose Studied with the FT-Raman Spectroscopy. IOP Conf. Ser.: Mater. Sci. Eng. 2019, 706, 012017.

(44) Alzeer, M.; MacKenzie, K. Synthesis and Mechanical Properties of Novel Composites of Inorganic Polymers (Geopolymers) with Unidirectional Natural Flax Fibres (Phormium Tenax). Appl. Clay Sci. 2013, 75-76, 148-152.

(45) Sankar, K.; Sá Ribeiro, R. A.; Sá Ribeiro, M. G.; Kriven, W. M. Potassium-Based Geopolymer Composites Reinforced with Chopped Bamboo Fibers. J. Am. Ceram. Soc. 2017, 100 (1), 49-55.

(46) Alomayri, T.; Shaikh, F. U. A.; Low, I. M. Characterisation of Cotton Fibre-Reinforced Geopolymer Composites. Composites, Part B 2013, 50, 1-6. 
(47) da Costa Correia, V.; Ardanuy, M.; Claramunt, J.; Savastano, H. Assessment of Chemical and Mechanical Behavior of Bamboo Pulp and Nanofibrillated Cellulose Exposed to Alkaline Environments. Cellulose 2019, 26 (17), 9269-9285.

(48) Lloyd, R. R.; Provis, J. L.; van Deventer, J. S. J. Pore Solution Composition and Alkali Diffusion in Inorganic Polymer Cement. Cem. Concr. Res. 2010, 40 (9), 1386-1392.

(49) Novais, R. M.; Seabra, M. P.; Labrincha, J. A. Porous Geopolymer Spheres as Novel PH Buffering Materials. J. Cleaner Prod. 2017, 143, 1114-1122.

(50) Brunauer, S.; Emmett, P. H.; Teller, E. Adsorption of Gases in Multimolecular Layers. J. Am. Chem. Soc. 1938, 60 (2), 309-319.

(51) Duxson, P.; Fernández-Jiménez, A.; Provis, J. L.; Lukey, G. C.; Palomo, A.; van Deventer, J. S. J. Geopolymer Technology: The Current State of the Art. J. Mater. Sci. 2007, 42 (9), 2917-2933.

(52) Masi, G.; Rickard, W. D. A.; Vickers, L.; Bignozzi, M. C.; van Riessen, A. A Comparison between Different Foaming Methods for the Synthesis of Light Weight Geopolymers. Ceram. Int. 2014, 40 (9), 13891-13902.

(53) MacKenzie, K. J. D. 28-Innovative Applications of Inorganic Polymers (Geopolymers). In Handbook of Alkali-Activated Cements, Mortars and Concretes; Pacheco-Torgal, F., Labrincha, J. A., Leonelli, C., Palomo, A., Chindaprasirt, P., Eds.; Woodhead Publishing: Oxford, 2015; pp 777-805 DOI: 10.1533/9781782422884.5.777.

(54) Luukkonen, T.; Sarkkinen, M.; Kemppainen, K.; Rämö, J.; Lassi, U. Metakaolin Geopolymer Characterization and Application for Ammonium Removal from Model Solutions and Landfill Leachate. Appl. Clay Sci. 2016, 119, 266-276.

(55) Luukkonen, T.; Věžníková, K.; Tolonen, E.-T.; Runtti, H.; Yliniemi, J.; Hu, T.; Kemppainen, K.; Lassi, U. Removal of Ammonium from Municipal Wastewater with Powdered and Granulated Metakaolin Geopolymer. Environ. Technol. 2018, 39 (4), 414-423.

(56) Zhang, J.; He, Y.; Wang, Y.; Mao, J.; Cui, X. Synthesis of a SelfSupporting Faujasite Zeolite Membrane Using Geopolymer Gel for Separation of Alcohol/Water Mixture. Mater. Lett. 2014, 116, 167170.

(57) Tang, Q.; Ge, Y.; Wang, K.; He, Y.; Cui, X. Preparation of Porous P-Type Zeolite Spheres with Suspension Solidification Method. Mater. Lett. 2015, 161, 558-560.

(58) Tang, Q.; He, Y.; Wang, Y.; Wang, K.; Cui, X. Study on Synthesis and Characterization of ZSM-20 Zeolites from MetakaolinBased Geopolymers. Appl. Clay Sci. 2016, 129, 102-107.

(59) Wang, H.; Yan, C.; Li, D.; Zhou, F.; Liu, Y.; Zhou, C.; Komarneni, S. In Situ Transformation of Geopolymer Gels to SelfSupporting $\mathrm{NaX}$ Zeolite Monoliths with Excellent Compressive Strength. Microporous Mesoporous Mater. 2018, 261, 164-169.

(60) Huang, P.; Kazlauciunas, A.; Menzel, R.; Lin, L. Determining the Mechanism and Efficiency of Industrial Dye Adsorption through Facile Structural Control of Organo-Montmorillonite Adsorbents. ACS Appl. Mater. Interfaces 2017, 9 (31), 26383-26391.

(61) Provis, J. L.; Lukey, G. C.; van Deventer, J. S. J. Do Geopolymers Actually Contain Nanocrystalline Zeolites? A Reexamination of Existing Results. Chem. Mater. 2005, 17 (12), 3075-3085.

(62) Rouquerol, J.; Avnir, D.; Fairbridge, C. W.; Everett, D. H.; Haynes, J. H.; Pernicone, N.; Ramsay, J. D. F.; Sing, K. S. W.; Unger, K. K. Recommendations for the Characterization of Porous Solids; International Union of Pure and Applied Chemistry, 1994, 66 DOI: $10.1351 /$ pac199466081739.

(63) Luukkonen, T.; Yliniemi, J.; Sreenivasan, H.; Ohenoja, K.; Finnilä, M.; Franchin, G.; Colombo, P. Ag- or Cu-Modified Geopolymer Filters for Water Treatment Manufactured by 3D Printing, Direct Foaming, or Granulation. Scientific Reports 2020, 10 (1) DOI: $10.1038 / \mathrm{s} 41598-020-64228-5$.

(64) Calvini, P.; Conio, G.; Lorenzoni, M.; Pedemonte, E. Viscometric Determination of Dialdehyde Content in Periodate Oxycellulose. Part I. Methodology. Cellulose 2004, 11 (1), 99-107.

(65) Clayden, J.; Greeves, N.; Warren, S.; Wothers, P. Organic Chemistry; Oxford University Press: Oxford, 2001.
(66) Sirviö, J. A.; Anttila, A.-K.; Pirttilä, A. M.; Liimatainen, H.; Kilpeläinen, I.; Niinimäki, J.; Hormi, O. Cationic Wood Cellulose Films with High Strength and Bacterial Anti-Adhesive Properties. Cellulose 2014, 21 (5), 3573-3583.

(67) Zhang, Y.; Jiang, J.; Chen, Y. Synthesis and Antimicrobial Activity of Polymeric Guanidine and Biguanidine Salts. Polymer 1999, 40 (22), 6189-6198.

(68) Hujaya, S. D.; Manninen, A.; Kling, K.; Wagner, J. B.; Vainio, S. J.; Liimatainen, H. Self-Assembled Nanofibrils from RGD-Functionalized Cellulose Nanocrystals to Improve the Performance of PEI/ DNA Polyplexes. J. Colloid Interface Sci. 2019, 553, 71-82.

(69) Tardy, B. L.; Ago, M.; Guo, J.; Borghei, M.; Kämäräinen, T.; Rojas, O. J. Optical Properties of Self-Assembled Cellulose Nanocrystals Films Suspended at Planar-Symmetrical Interfaces. Small 2017, 13 (47), 1702084.

(70) Pacaphol, K.; Aht-Ong, D. The Influences of Silanes on Interfacial Adhesion and Surface Properties of Nanocellulose Film Coating on Glass and Aluminum Substrates. Surf. Coat. Technol. 2017, 320, 70-81.

(71) Laitinen, O.; Suopajärvi, T.; Österberg, M.; Liimatainen, H. Hydrophobic, Superabsorbing Aerogels from Choline Chloride-Based Deep Eutectic Solvent Pretreated and Silylated Cellulose Nanofibrils for Selective Oil Removal. ACS Appl. Mater. Interfaces 2017, 9 (29), 25029-25037.

(72) Bai, C.; Colombo, P. High-Porosity Geopolymer Membrane Supports by Peroxide Route with the Addition of Egg White as Surfactant. Ceram. Int. 2017, 43 (2), 2267-2273.

(73) Salvini, V. R.; Luchini, B.; Aneziris, C. G.; Pandolfelli, V. C. Innovation in Ceramic Foam Filters Manufacturing Process. Int. J. Appl. Ceram. Technol. 2019, 16 (1), 378-388.

(74) Shivaraju, H. P.; Egumbo, H.; Madhusudan, P.; Anil Kumar, K. M.; Midhun, G. Preparation of Affordable and Multifunctional ClayBased Ceramic Filter Matrix for Treatment of Drinking Water. Environ. Technol. 2019, 40 (13), 1633-1643.

(75) Masturi, S.; Aji, M. P.; Sustini, E.; Khairurrijal, M. A. Permeability, Strength and Filtration Performance for Uncoated and Titania-Coated Clay Wastewater Filters. Am. J. Environ. Sci. 2012, 8 (2), 79-94. 